\title{
Existence and Flow Behavior of Gas at Low Saturation in Geopressured Formations - Final Report
}

Published April 1979

Prepared for

U.S. Department of Energy

Assistant Secretary for Energy Technology

Division of Geothermal Energy 
Available from:

National Technical Information Service (NTIS)

U.S. Department of Commerce

5285 Port Royal Road

Springfield, Virginia 22161

Price: Printed copy: $\$ 4.50$

Microfiche: $\$ 3.00$ 


\section{DISCLAIMER}

This report was prepared as an account of work sponsored by an agency of the United States Government. Neither the United States Government nor any agency Thereof, nor any of their employees, makes any warranty, express or implied, or assumes any legal liability or responsibility for the accuracy, completeness, or usefulness of any information, apparatus, product, or process disclosed, or represents that its use would not infringe privately owned rights. Reference herein to any specific commercial product, process, or service by trade name, trademark, manufacturer, or otherwise does not necessarily constitute or imply its endorsement, recommendation, or favoring by the United States Government or any agency thereof. The views and opinions of authors expressed herein do not necessarily state or reflect those of the United States Government or any agency thereof. 
HCP/T2259-05

Dist. Category UC-66a

\section{Existence and Flow Behavior of Gas at Low Saturation in Geopressured Formations - Final Report}

Published April 1979

Prepared by

Charles S. Matthews

Under Contract No. EW-78-X-05-2259

Prepared for

U.S. Department of Energy

Assistant Secretary for Energy Technology

Division of Geothermal Energy

Washington, D.C. 20545

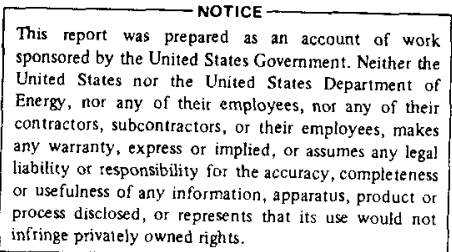




\section{NOTICE}

This report was prepared as an account of work sponsored by the United States Government. Neither the United States nor the United States Department of Energy, nor any of their employees, makes any warranty, express or implied, or assumes any legal liability or responsibility for the accuracy, completeness, or usefulness of any information, apparatus, product, or process disclosed, or represents that its use would not infringe privately owned rights. Reference herein to any specific commercial product, process, or service by trade nome, mark, manufacturer, or otherwise, does not necessarily constitute or imply its endorsement, recommendation, or favoring by the United States Government or any egency thereof. The views and opinions of authors expressed herein do not necessarily state or reflect those of the United States Government or any agency thereof. 


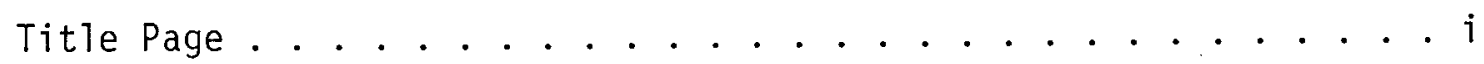

Contents......................... $i i$

List of Figures..................... i . . . . . . .

Abstract .................. . . $v$

I. Introduction ................... . . 1

II. How Trapped Gas Saturations Develop During Water Invasion of a

Gas Sand.................. 2

III. How Low Gas Saturations Develop During Gas Invasion of a

Water Sand ................. 5

IV. How Low Gas Saturations Dissipate. . . . . . . . . . . . 7

V. Recent Evidence for Low Gas Saturations. . . . . . . . 10

VI. Detection of Low Gas Saturations... . . . . . . . . 12

VII. Behavior of Low Gas Saturations During Flow in a Reservoir . . 13

VIII. Conclusions. . . . . . . . . . . . . . . 17

IX. References................. 18

X. Appendices . . . . . . . . . . . . . . .

A. Appendix 1................ . 20

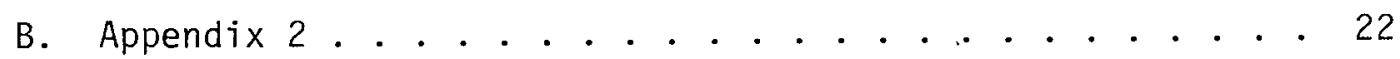

C. Appendix 3................... 25

D. Flow Data Sand No. 1............... 27

E. Flow Data Sand No. $3 \ldots \ldots$. . . . . . . . . 28 


\section{FIGURE}

TITLE

Geographic Location of Well

Number 2 and Number 3 Sands, Edna Delcambre No. 1

Number 1 Sand, Edna Delcambre No. 1

Structure Map, Number 1 Sand 2

A Doublet Pore 3

Trapping of Gas by Invading Water 3

Gas and Water Relative Permeability Curves 4

Migration of Gas 5

Gas Invading Water Filled Pore Space 5

Gas and Water Relative Permeability Curves 6

Capillary Pressure

Velocity in Unconsolidated Sand Containing Water and Air

Sonic Log

Gas Bubble in a Doublet Pore

Pressure Distribution During Flow

Solubility of Gas and Water Produced

from No. 3 Sand

Test Data - Number 1 Sand

Average Gas Water Ratio vs. Cumulative Water Production for Sand No. 1 


\section{LIST OF FIGURES}

FIGURE

20

21

22
TITLE

Test Data - Number 3 Sand

Zones of Petroleum Generation and Destruction

Petroleum Generation Profile for the Gulf Coast
FOLLOWS

PAGE

23

26

26 


\section{EXISTENCE AND FLOW BEHAVIOR OF GAS AT LOW SATURATION}

IN GEOPRESSURED FORMATIONS

by C. S. Matthews

\section{ABSTRACT}

The first geopressured brine well tested for the Department of Energy produced gas and brine at a ratio far above the solution ratio for the gas in that brine. One explanation advanced was that the geopressured formation contained gas at a low saturation, and that this gas flowed into the well during the test. This hypothesis is examined in this paper and found to be untenable based on evidence from well logs, flow tests and thermodynamics, and on currently accepted concepts for migration and accumulation of petroleum. The probable explanation for the observed high gas/water ratios is shown to be a thin, tight gas-bearing layer in the case of one sand and an updip gas cap in the case of the second sand tested. 


\section{EXISTENCE AND FLOW BEHAVIOR OF GAS \\ AT LOW SATURATION IN GEOPRESSURED FORMATIONS}

by $C$. S. Matthews

\section{INTRODUCTION}

A very interesting and potentially very important phenomenon occurred during flow testing of well Edna Delcambre No. 1, Vermillion Parish, Louisiana, (see Figure 1) in June of 1977. The we11, which was being tested by OHRW Engineering for the Energy Research and Development Administration (now the Department of Energy) had been expected to produce geopressured brine, probably saturated with methane. However, both the number 3 and the number 1 sands tested (see Figures 2 and 3) produced gas (mainly methane) at a gas/liquid ratio far above the solution ratio. Only about 20-24 std. cu. ft. of produced gas could be dissolved in each barrel of produced water in laboratory recombination studies. However, both sands produced gas and water at ratios up to 50-60 cu. ft. per bbl. for extended periods.

A number of explanations have been advanced to explain this behavior. In the case of sand number 3 , the streak of high resistivity rock near the top (the interval 12,873'-12,876' on Figure 2) is almost certainly gas bearing. The author had suggested this in a letter to ERDA prior to logging and recompletion of the well in the number 3 sand. Running of the TDT $\log$ and analysis of this $\log$ and the resistivity $\log$ has confirmed this first interpretation, and has indicated that this interval is probably both tight and gas bearing. A more complete discussion of the behavior during flow testing is given in Appendix 2 .

The behavior of sand number. 1 is more puzzling. There is no evidence from logs that the sand is gas bearing. One possible explanation 
is that gas production is from the gas cap that exists just updip of the top of the completion interval in sand number $1^{*}$. Production of water could have "coned" the gas down into the well. It is also possible that gas from sand number 2 or number 3 (see Figure 2) reached sand number 1 because of a poor cement job in the cemented liner that exists in the interval between sands number 1 and number 3 . Practice has shown that it is very difficult to obtain a perfect cement job when landing and cementing a liner at these depths.

Still another intriguing explanation of the gas production from sand number 1 is that gas exists throughout sand number 1 , but at a very low saturation of about $2-5 \%$. At such low saturation the gas would not flow when there was no pressure gradient. However, when the well was placed on production and a pressure gradient established, it has been postulated that this gas might flow. This last explanation will be examined in this paper.

This possible explanation will be examined by first discussing how gas saturations could arise in a geopressured formation. Then, some past work with regard to low gas saturations will be discussed along with some recent evidence for their existence, how low gas saturations can be detected, and whether field measurements indicate the presence of low gas saturations in the tested sands in Edna Delcambre No. 1. Finally, the behavior of low gas saturations during flow in a reservoir will be described, followed by our conclusions as to whether this gas was a significant factor in the test behavior of Delcambre No. 1 .

HOW TRAPPED GAS SATURATIONS DEVELOP DURING WATER INVASION OF A GAS SAND

Invasion of a gas sand by water - Consider a gas reservoir where the pore space is filled only with gas and interstitial water.

\footnotetext{
* See Figure 4, which is taken from reference 1. The gas/water contact in sand number $1\left(-12,407^{\prime}\right)$ was some $117^{\prime}$ higher than the top of sand number 1 in Delcambre No. $1\left(-12,524^{\prime}\right)$. Thus a pressure drop of only about 50 psi at this point could "cone" gas down to Delcambre No. 1. Table 1 of this report (page 14) shows that a pressure drop of $350 \mathrm{psi}$ could have occurred at the gas/water contact, during high water rate testing in sand number 1. Thus one possible source of gas production in sand number 1 is the gas cap shown in Figure 4. The test well behavior (higher gas/water ratio in sand number 1 at higher water rate) is also consistent with "coning" down of gas from the updip gas cap as discussed in Appendix 2.
} 
Two interconnected pores in such a reservoir are shown schematically in Figure 5. In nearly al1 underground porous rocks, there is a strong attractive force between the rock surface and water. This attraction is particularly strong between sandstones which are composed mainly of silica, and water, which is polar. Evidence of this attractive force is given by the rise of water in a glass (silica) capillary. The inability to drain all the water from a sand pack is evidence of this same attraction. See reference 2 for a more complete discussion. Because of the stronger attraction between the rock and the polar water molecules, the finer pores and crevices of the porous rock will be filled with water while the larger pores will be filled with gas. In this configuration with water in the finer pores and gas in the larger pores, the surface (free) energy of the system is at a minimum, and thus the system is at equilibrium. Suppose this reservoir is now flooded by water introduced by natural water influx or from a water injection wells.

As the water invades the reservoir, it will advance fastest thru the smaller pores* where it will seal off and trap gas in the larger pores (see Figure 6). This disconnected gas can no longer flow and becomes "residual" gas. The reason this gas is trapped is that the pressure gradient in the water is not sufficient to deform the gas and move it thru the constrictions in the porous rock. These constrictions are shown schematically in Figure 6 at each end, where the pores converge. To remove the gas, either the interfacial tension must be reduced to a very low level (about $10^{-3}$ dynes/cm or lower), or an extremely high pressure

\footnotetext{
*The capillary pressure, $P_{C}$, across a gas/water interface in a pore is given by $P_{C}=2 \gamma \cos \alpha / r$, where $\gamma=$ interfacial tension, $\alpha=$ contact angle, and $r=$ radius of curvature. As the water invades from the left in Figure 5 , it will reach the neck where it must divide between the large pore and the small pore. At this point, the much larger capillary pressure drop across the gas/water interface in the small pore will "pull" the water through that pore. Thus it will quickly reach the other end of the pore and trap residual gas as shown in Figure 6 .
} 
gradient some 1000 times greater than normal must be applied. As the wellbore pressure required to generate such a gradient would fracture the reservoir rock near the we11, this gas is, for practical purposes, trapped and unrecoverable.

Saturation of gas trapped by invading water - The quantitative relationship between permeability to a flowing phase (water, oil or gas) and the saturation of that phase must be measured experimentally in the laboratory for each porous rock of interest. Results are usually displayed as a curve of relative permeability (\% of absolute permeability) versus saturation of a phase. Typical curves for gas and water relative permeability are shown in Figure 7.

The trapped or residual gas saturation is shown to be $20 \%$. Note that the relative permeability to water at this saturation is still low (about $30 \%$ ). This is because the water, as the wetting phase, tends to occupy, preferentially, the smaller pores where the flow resistance is much higher than in the larger pores, occupied by gas.

The mechanism by which advancing water is able to trap relatively large volumes of residual gas is illustrated in Figures 5 and 6 . An increase in water saturation in a porous rock has been termed "imbibition". The following section is quoted (but restated for gas) from Frick, "Petroleum Production Handbook", page 25-28.

"In brief, as water is progressively imbibed into gas-filled pores of different sizes, gas is ejected from them. The ejection process continues so long as continuous escape paths via pores are available. It is found in practice that these escape paths appear to be lost at gas saturations which greatly exceed those which characterize the onset of continuity of gas on the drainage (of water) cycle. That is, the residual gas saturation which results from waterflooding a water-wet rock is much greater than the equilibrium or critical gas saturation (i.e. the onset of gas continuity as gas is introduced to a water saturated porous rock.) that characterizes the same rock. Apparently on the imbibition 
cycle the gas is trapped in islands. Typically the residual gas saturations lie in the range of 15 to 50 percent of pore space while equilibrium or critical gas saturations in the same preferentially water-wet rock range from 1 to 15 percent pore volume."

Detection of gas trapped by water - The saturation of gas that can be trapped by an advancing water front is rather high. The exact value depends on the pore structure of the rock. A range of $15 \%$ to $50 \%$ trapped gas is most common. 3

If such a large trapped gas saturation existed in sands number 1 or 3 in Delcambre No. 1, it would be relatively easy to detect with well logging tools. The rock resistivity would be quite high, relative to a completely water saturated section of the same porosity. In addition, the hydrogen content would be low, relative to a water saturated section of equal porosity. Analysis of the resistivity and neutron logs indicated that such a saturation clearly does not exist in the high porosity portions of the number 1 and number 3 sands in Delcambre No. 1 .

HOW LOW GAS SATURATIONS DEVELOP DURING GAS INVASION OF A WATER SAND

Invasion of a water sand by gas - A non-flowing gas saturation can arise in another way. As gas is generated in deeply buried marine shales, it will enter adjacent sands and migrate upwards in these to a trap (see Figure 8). In finding a trap, the gas could move up a fault, reach a geopressured sand, and move through the sand on its way to another fault.

Under these conditions, the gas saturation is established by gas invading a water-filled porous rock, rather than the converse. The gas saturation necessary to establish continuity (and thus flow) under such conditions can be quite low. This is the "critical" gas saturation. Generally, a saturation of about $5 \%$ is sufficient to sustain some flow. See the discussion in reference 3, p. 25-8. This situation is illustrated in Figure 9, where gas has established a continuous path by displacing the water from the large pore.* Since gas is "non-wetting", it will continue

*It may not be apparent from Figure 9 that gas can establish a continuous path at low gas saturation. However, by linking up only a few large pores, as shown, continuity can be established across a considerable length of porous rock. 
to seek out and to occupy these larger pores as it flows through the porous rock. As the large pores have the lowest resistance to flow, the gas will acquire a significant permeability at quite a low gas saturation.

The quantitative relationship between the ability of gas to flow and the gas saturation must be measured experimentally in the laboratory for each porous rock of interest. Typical curves are shown in Figure 10 (from reference 3 ) for gas invading a water-filled porous rock. For this porous rock, the "critical" gas saturation is about $5 \%$. Likelihood of a uniform "critical" gas saturation - Is it plausible that the gas saturation which might arise by migration of gas through a geopressure zone would be rather low and uniform throughout that sand? To seek an answer to this question we return to Figure 8.

For the deeper sand near the shales where gas is being generated (the bottom sand on Figure 8 ), the gas saturation could build up and only slightly exceed the critical saturation throughout that sand, particularly in a sequence of thin sands and shales. However, the gas which migrates to the fault and thru the next geopressured sand will seek the top of that sand. At the top, the gas saturation will increase to a saturation value and a thickness great enough to carry off the migrating gas. This will be discussed in the following paragraph.

Gas saturation near the top of a sand - The pressure required to cause migrating gas to enter a water-filled sand is given by the capillary pressure*. A typical capillary pressure curve for a $300 \mathrm{md}$ rock is given in Figure 11 (from reference 3 ). For this example, it may be seen that the initial pressure required to force gas (which is migrating up a fault) into the water-filled porous sand is 2 psia. As the pressure is increased an additional 1 psi (to 3 psi), the gas saturation rises to about $70 \%$. A pressure difference of 1 psi would only drop the gas/water contact in the fault zone about two feet

*The gas-water capillary pressure, at a given saturation, is the excess pressure (above that in the water) required to force gas into the waterfilled porous medium. See footnote on page 3 . 
$(1 / .465=2.15 \mathrm{ft}$.$) . Thus, the gas saturation will increase rapidly at$ the top of the sand, rather than uniformly over the entire sand.

If the thickness of the layer of high gas saturation at the top of the sand is not great enough to carry off gas at the rate at which it is migrating, that thickness will tend to increase to give the required capacity. In any event, in a permeable sand, the gas saturation caused by migrating gas would tend to be concentrated near the top of the sand. From published data ${ }^{4}$ on rates of generation of hydrocarbons, we can calculate the expected thickness of migrating gas. Typical values range between a few inches and several feet.

Thus, we conclude that we would not expect to find a low "critical" gas saturation throughout the entire thickness of a permeable sand such as that in Edna Delcambre No. 1, but would expect to find any remaining gas only near the top of the sand body.

HOW LOW GAS SATURATIONS DISSIPATE

Dissipation of a gas saturation - If a gas saturation is formed, what are the forces that will tend to dissipate it? First of all, we note that the interface between gas and water is concave toward the gas, as illustrated in Figure 5 . This shape arises because the water wets the rock surface in preference to gas. Because of this shape, the pressure in the gas phase is slightly higher than the pressure in the water phase across the interface. The magnitude of this excess pressure is inversely proportional to the radius of curvature of the interface. Thus small gas bubbles would have a higher gas pressure than larger ones.

Because of this excess pressure the gas in the smaller gas bubbles will tend to dissolve into the water, to diffuse into and to swell the larger gas bubbles. In addition, the hydrostatic pressure and the temperature are higher at the bottom of the water sand than at the top. This will also cause the gas at the bottom to dissolve at the bottom and to come out of solution at the top of the sand column.

The net effect of these forces is to cause gas to collect at the top of a water sand and thence to move updip. 
Time for dissipation of a gas saturation - To calculate the time required for this saturation to dissipate is difficult to do with exactness. We can, however, compute an order of magnitude of maximum time from the diffusion constant for methane dissolved in water. The excess pressure in the methane trapped as a gas bubble at the bottom of a $30^{\prime}$ sand will be about $.465 \times 30=14 \mathrm{psi}$. Thus, a methane concentration gradient from bottom of sand to top is caused by this 14 psi excess pressure.

We estimate that under current conditions in the number 3 sand it would take a $20 \%$ gas saturation at the bottom of a $30^{\prime}$ 'sand some 6 million years to reach the top (see Appendix 1).

These calculated times, though approximately correct for current conditions, are too long for rates of gas dissipation when the number 1 and number 2 sands were at shallower depths. At shallower depths, the rate of change of gas solubility with pressure is much higher (by a factor of about 10). In addition, the effect of temperature, neglected in the first calculation in Appendix 1, will increase the rate about $30 \%$. Finally, the effect of disappearance of small bubbles and the increase in size of large ones was also neglected in our first calculation. When we take all these effects into account, as outlined in Appendix 1, we estimate that at a pressure of $3000-4000 \mathrm{psi}$ it would take a $20 \%$ gas saturation at the bottom of a $30^{\prime}$ sand some 0.5 million years to reach the top. Thus the gas is moving up with a transit time of about 20,000 years per foot of height. This rate is still low.

Source of gas produced from Delcambre No. I - Is it possible that gas is currently being generated in the shales adjacent to sands number 1 and number 3 ? If so, this could produce a rather uniform, low saturation level of gas.

To answer this question, we refer to Dow ${ }^{4}$, as discussed in Appendix 3. His paper indicates that generation of essentially dry* methane (which is what we see in sands number 1 and number 3 ) does not begin in the Louisiana Miocene until a depth of about 20,000 ft. is reached.

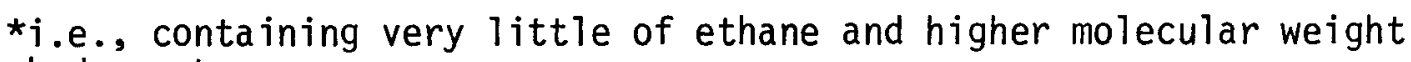
hydrocarbons 
The great depth required for generation in this case is caused by: (1) the low geothermal temperature gradient on the Gulf Coast, and (2) the relatively rapid rate of deposition of the Miocene. Because of these two factors, the organic material in the Miocene shales at the 12,000' levels will not have been subjected to the necessary temperature for the necessary time for conversion to methane. Dow based his estimate of the depth required for dry gas generation on the measurement of vitrinite reflectance. This approach is generally considered to be the most reliable technique available for obtaining the maturity level of sediments for generation of hydrocarbons. See Appendix 3 for a more thorough discussion.

We thus conclude that the shales adjacent to sands number 1 and number 3 could not currently be generating the gas produced with the water.

It is most likely that any gas present in the Miocene sands of interest in Delcambre No. 1 would have come from deeper marine shales, ${ }^{4}$ where it was formed. As we discussed, it is also most likely that during migration and accumulation, such gas would collect at high saturation near the top of the sand member, rather than spreading out over the thickness of the sand. Thus it appears that any gas would have been at high saturation at one time.

Why and how would that gas saturation decrease? This would happen as the gas continued to move updip, collecting in a trap. As the gas saturation decreased, water would replace it by imbibition. The final disconnected, residual gas saturation in such a case would be rather high, like that after a water drive in a gas reservoir.

Thus we conclude that, if the source of gas in a geopressured water sand is from a deeper source rock, then any gas saturation should have the following characterisitics:

1) Should be concentrated within a few feet of the top of a sand member, and

2) Should be at a rather high saturation of say $20 \%$ or more, even if it is at a residual saturation.

Such a gas saturation should be relatively easy to detect by conventional well logs. 
In the next section, we will discuss another possible source for gas in geopressured zones. However, by far the most common source of gas is migration from deep source rocks, as discussed above.

\section{RECENT EVIDENCE FOR LOW GAS SATURATIONS}

Seismic evidence - Ritch and $S_{m i t h}^{5}$ have discussed this evidence in some detail. The phenomenon was brought to light when several subsurface sands, which had appeared to be gas-filled on the basis of their seismic reflectivity, were found on drilling to contain mainly water with gas present but at low saturation. A number of these sands containing gas at low saturation have now been confirmed by pnoduction testing.

As discussed previously, the presence of even a small saturation of gas (1-2\%) lowers the velocity of sound significantly and thus produces a high amplitude reflection. These high amplitude reflections (termed "bright spots") are often indicators of the presence of hydrocarbons. The fact that high amplitude reflections occur when the gas saturation is low as well as high has led to intensive investigation, as will be discussed below.

Drilling and production evidence - What could be the source of such gas of low saturation? Ritch and $\mathrm{Smith}^{5}$ have determined the ratio of $C_{13}$ to $C_{12}$ in the methane gas in several of these accumulations in an attempt to answer this. The lower than normal ratio of $\mathrm{C}_{13}$ to $\mathrm{C}_{12}$ in the methane indicated a biogenic origin for the methane. The hypothesis is that this gas is currently being generated by bacteria. As a source, the bacteria apparently use the organic material in the sands.

Could these same bacteria now be generating methane in sands number 1 and 3 ? The evidence says no. The maximum temperature at which bacteria can exist is about $160^{\circ}-170^{\circ} \mathrm{F}$. Thus, they could not now be functioning in shales at temperatures of about $238^{\circ} \mathrm{F}$ in sands number 1 and number 3 .

Could the gas found dissolved in the water in sands number 1 and number 3 be of biogenic origin? The answer is "possibly", as will be discussed below: 
At a temperature of $170^{\circ} \mathrm{F}$, the depth of burial of sediments at the location of Delcambre No. 1 would have been about 7000'. The hydrostatic pressure at this depth would have been about 3200 psi. The solubility of methane in fresh water at $3200 \mathrm{psi}$ and $170^{\circ} \mathrm{F}$ is about $16 \mathrm{SCF} / \mathrm{bb} 1.6$ If we estimate that the salinity was at least $50,000 \mathrm{ppm}$ at that time, the maximum solubility was about $13 \mathrm{SCF} / \mathrm{bbl} .^{7}$ However, if a small free gas saturation had existed at that time, some additional gas could have been put into solution as the sand was buried more deeply. The tendency of any free gas to move upward in the sand by diffusion thru the water would tend to limit the amount available to go into solution.

In conclusion, we can say that the 20-24 SCF/bbl. of gas

dissolved in the waters of Delcambre No. 1 might have had a biogenic origin. An analysis to determine carbon-13 content would prove whether this was or was not the origin.

Could a free gas saturation which had formed biogenically at shallower depths persist as the sands were buried more deeply? Could the free gas have persisted as a uniform saturation during burial from say $7000^{\prime}$ to $11,000-12,000^{\prime}$ ? Our answer to this is no. The time required for burial from $7000^{\prime}$ to $12,000^{\prime}$ is a few million years. ${ }^{4}$ We calculated earlier, that during this time a gas saturation of $20 \%$ would have been dissipated at an initial rate of about 10,000 years per foot of vertical thickness. The biogenic gas now being found at shallow depths appear to be at about $5 \%$ saturation or less. The time required for a $5 \%$ gas saturation to disperse is only $1 / 4$ the time required for a $20 \%$ saturation. Thus in a 30 ' sand thickness containing about $5 \%$ gas saturation, the gas would have dissipated in $30(10,000) / 4=75,000$ years. This is so much less than the time of burial from $7000^{\prime}$ to 11,000 ' that no biogenic free gas could be left.

Conclusion with relation to Delcambre No. 1. - Although we can build a plausible case for the existence of methane saturated water in sands number 1 and number 3 (via migration from deeper source beds), we are unable to build a case for a uniform free gas saturation. Neither shallow biogenic or deep source rock origin appears to have been capable of maintaining a low, rather uniform "critical" gas saturation throughout 
the sands under study. Either source could have developed the methane dissolved on the water.

DETECTION OF LOW GAS SATURATIONS

Logs - The well log which will show up gas saturation most clearly is the sonic log. The relationship between gas saturation and sonic velocity is given by Gassman's equation, as shown in Figure 12, from Flowers ${ }^{8}$. Note that presence of only a 1-2\% gas saturation is predicted to lower the sonic velocity from $7500 \%$ second, to less than $5000 \% /$ second. Measured values did not take quite so drastic a drop, although the measured drop was severe. Ritch and Smith ${ }^{5}$ attribute this to an inability to achieve a uniform gas saturation in the small core. If paths of high liquid saturation exist for the sound waves, the measured velocity will be higher than predicted for a uniform saturation.

Data from Delcambre No. 1 - We begin our analys is of the Sonic Log in Figure 13 with sand number 3 . As we had discussed previously, the interval $12,873^{\prime}-76^{\prime}$ is almost certainly gas bearing, but has a much lower porosity than the underlying sand. The effect of the large change in porosity (from $30 \%$ to $20 \%$ ) overrides the effect of change in fluid content. The sonic velocity is higher (transit time is lower) in this tight streak than in the ma in body of the sand. Another tight streak shows up at $12,909^{\prime}-11^{\prime}$ in Figure 13. (The TDT log of Figure 2 confirms this as an interval of slightly lower porosity.) We note on Figure 13 that the transit times in the main No. 3 sand body are about 90 micro-seconds/ft. In the shale just above sand number 3 , the transit times rise to 115 micro-seconds/ft.

In sand number 2, we again see a high velocity tight streak at the top of the sand in the interval 12,816-20'. The sonic velocity in the remainder of that sand is about the same as that in sand number 3.

In sand number $\mathrm{l}$, the transit time was almost constant at $100 \mathrm{~ms} / \mathrm{ft}$. in the perforated interval of 12,573-605'.

The effect of a gas saturation would be to increase the transit time. We see no evidence of any shift in transit time with depth in sand 
number 1. Thus if there is any free gas saturation, it must be extremely un iform.* We are led to the same conclusion in sands numbers 2,3 , and 4 . For 211 these sands to have exactly the same residual gas saturation would be very unlikely. And since even a small gas saturation would significantly decrease the sonic velocity, it is virtually certain that the sands in question do not contain a small non-flowing gas saturation.

BEHAVIOR OF LOW GAS SATURATIONS DURING FLOW IN A RESERVOIR

We will now discuss the behavior of gas dissolved in water as the pressure is reduced.

"Critical" gas saturation and its development during pressure reduction - As discussed, a critical gas saturation develops as gas invades a liquid-filled porous rock. The source of the gas can be "external" as in Figure 8 and already discussed or "internal", from solution in oil or water. Studies of this latter phenomenon have been made in connection with studies of solution-gas evolution from oil. In the following paragraphs we will discuss development of such a gas saturation. Although discussed for oil, we would expect the same phenomena for water.

As the pressure declines in an oil reservoir it will reach the saturation pressure at which gas will tend to evolve from the oil. Studies $9,10,11$ have shown that in oil reservoirs, little supersaturation is possible because of the low rate of pressure decline. These studies further indicate that, because of the slight degree of supersaturation which can occur in an oil reservoir, a gas bubble does not initially occur in every pore. Rather a gas bubble forms initially in only about every 20 cubic inches ${ }^{11}$. Such bubbles cannot flow, as illustrated in Figure 14, because they soon become too large to pass thru the pore constrictions.

Once a gas bubble forms, and if pressure continues to decrease, that gas bubble will grow in size by diffusion of gas through the oil

*The effect of invasion of the sand by mud filtrate would be to tend to dissolve any free gas. However, the interval was drilled with a low water loss mud. Thus it is very unlikely that enough mud filtrate entered to dissolve the free gas in the volume around the well investigated by the sonic log. 
to the bubble. At rates of pressure decrease experienced in oil fields, no other bubble will form within a few cubic inches around each initial bubble. Diffusion of gas, it can be calculated, is fast enough in such a volume to prevent any supersaturation and this formation of any additional bubbles.

As the gas bubbles grow, they eventually link up throughout the pore structure of the reservoir rock. The saturation at which this occurs depends on the distribution of pores. If there is a continuous distribution of pore sizes, with some well-connected large pores throughout, the gas wi 17 connect at a very low gas saturation, say $1 \%$ of pore space. For a system with a more uniform set of pores the saturation for connection (critical gas saturation) will be somewhat higher, say $2-5 \%$. This is the range we would expect for the rather permeable number 1 and number 3 sands found in Edna Delcambre No. 1 . Thus, if a gas saturation arose via pressure reduction we would expect its"critical" saturation to be $10 \mathrm{w}$, say $2-5 \%$. If the gas saturation builds up to a value greater than this the gas will flow. If the saturation is less it is trapped and will not flow.

Flow at some distance from a wel1 - As may be seen from

Figure 15, the pressure drop during flow into a well is concentrated in a region near the well. The following table illustrates this for single-phase, steady state flow, and a 2000 psi pressure drop between an outer radius of $5000^{\prime}$ and the wellbore.

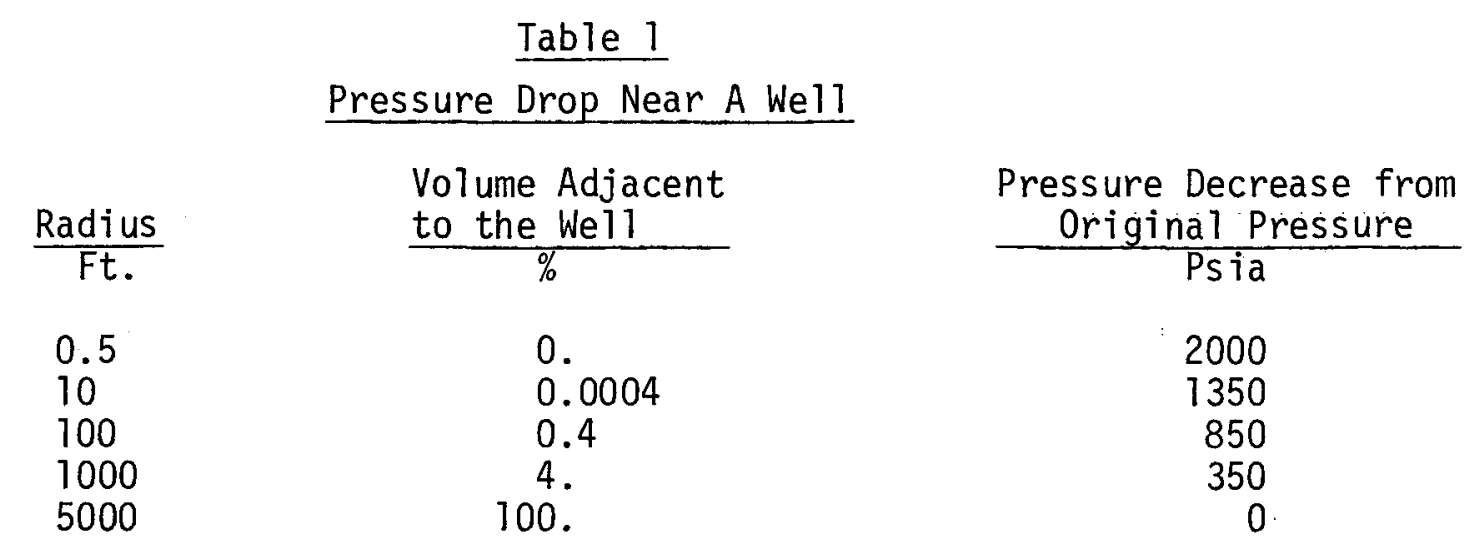

Note that in $96 \%$ of the reservoir (from $1000^{\prime}$ radius to $5000^{\prime}$ radius) the pressure has decreased from the original value by 350 psi or less. At the well itself, the pressure has decreased by 2000 psi. 
Thus nearly all of the pressure decrease occurs relatively near the well. When there is a zone of low permeability near the we 11, even more of the pressure drop will occur in this region.

The consequence of this with regard to flow of water saturated with methane may be found from Figure 16. This figure shows the amount of methane dissolved at various pressures in the brine contained in sand number 3 in Delcambre No. 1.* Note that a pressure drop of 2000 psi releases only $0.2 \mathrm{SCF}$ of methane/bbl. At reservoir conditions of 11,000 psi and $238^{\circ} \mathrm{F}$, this will increase the gas saturation by $0.007 \%$. Similarly, a pressure decrease of 350 psi would increase the gas saturation by only $0.001 \%$.

A change in gas saturation of $0.001 \%$ is far less than the "critical" gas saturation and would not significantly alter the relative permeability to gas. Therefore, if gas was not $f 1$ owing in $96 \%$ of the reservoir volume prior to this change, it would still not flow at this slight additional gas saturation.

As the reservoir pressure decreases with continued production of water, gas can come out of solution and increase the gas saturation. We can calculate the amount of this increase from the solubility curve for gas in water (Figure 16). The maximum pressure decrease which can occur in a flowing geopressured water well is from initial geopressure to hydrostatic. At the latter pressure the well will no longer flow. For Delcambre No. 1, the maximum decrease in pressure is from about 11,000 psi to about $6000 \mathrm{psi}$. We see from Figure 16 that this pressure decrease will cause the evolution of one cu. ft. of methane per bbl. of water. Under reservoir conditions (6000 psi and $238^{\circ} \mathrm{F}$ ) this wi11 increase the gas saturation by $0.06 \%$. This is still far less than the critical gas saturation. Therefore, in the bulk of the reservoir, only gas saturated water will flow toward the producing well.

*This data shows that only 18 std. cubic feet of gas could be dissolved in each barrel of water. Later experimental data showed that 20-24 $\mathrm{cu}$. ft./bbl. Was more representative. Our discussion would be esentially unchanged for these slightly larger valves. 
Flow near the well - Near the wel1, the situation is somewhat different from that in the bulk of the reservoir. All of the water that is produced (by expansion in the bulk of the reservoir) must pass thru the radii near the well. The reservoir volumes out to a radius of several hundred feet are too small to expand appreciably. Thus the volume in a $30 \mathrm{ft}$. thick, $28 \%$ porosity sand to a radius of $100 '$ is only $46,000 \mathrm{bbl}$. If this volume produced $5 \%$ of its volume by expansion, the total production would only be $2300 \mathrm{bbl}$. Thus when production is by fluid expansion, the volumes near the wellbore are, for practical purposes, inconsequential.

As the liquid is produced and as the fluids expand in the bulk of the reservoir, these fluids flow to the wellbore, their pressure dropping as illustrated in Figure 15.

As the pressure drops near the well, gas will evolve from solution in the water and will begin to build up a gas saturation. This build up will be the largest very near the wellbore where the pressure drop, and thus the gas evolved is the greatest.

For a time, the gas evolved from the liquid will not flow out. Thus, the first liquid to be produced should be saturated under the pressure at the wellbore itself. Shortly after this, however, the evolved gas will increase the gas saturation until gas flow takes place. A quasi-steady state will then result where the incoming water drops in pressure and evolves gas. The evolved gas and the water will then be produced in the same ratio as that at which gas was dissolved at the current average reservoir pressure.

The above may be seen from Figure 17. For simplicity, we have divided the reservoir into two zones, one from the wellbore to a radius of $100^{\prime}$, and the second from $100^{\prime}$ to $500^{\prime}$. As we have shown, only methane-saturated water flows across the $100^{\prime}$ radius. Therefore, at steady state, the ratio of methane and water produced from the well cannot be higher than that entering the $100^{\prime}$ radius.

Prior to steady state, the gas saturation will increase near the well as gas comes out of solution in the water. Any increase in 
gas saturation in the region near the wellbore will decrease the production rate of gas temporarily. This will lower the produced gas/water. Thus the region around the wellbore is a local "sink" for gas. For the produced gas/water ratio to rise above the solution ratio, as occurred in Delcambre No. 1, we need some source of gas rather than a sink.

We may summarize by stating that there does not appear to be any mechanism whereby the gas/liquid ratio in Delcambre No. 1 could rise appreciably above the solution ratio, unless there is some extraneous source of gas such as a nearby gas cap, or an adjacent sand containing gas and a leaky cement job on the casing.

CONCLUSIONS

In this study we have reached the following conclusions:

1) It is highly unlikely that a uniform low gas saturation exists in sands numbers 1 and 3 in Delcambre No. 1. The forces of capillarity and diffusion are shown to be fast enough during the time of burial or the time of gas migration thru the sand to cause movement to the top of the sand, and thence updip.

2) Even if a uniform, non-flowing gas saturation did exist, it could not account for the observed high gas/water production ratios in Delcambre No. 1 .

3) As a consequence, the source of the high gas/water production ratios must be:

A. A gas layer, as in sand number 3 , and

B. An updip gas cap, which occurs in sand number 1, or

C. A poor cement job which allows gas from sands numbers 2 or 3 to reach sand number 1 . 


\section{REFERENCES}

1. Karkalits, 0.C., Hodges, Jimmie, and Jones, Paul, "Investigation and Definition of Parameters Associated with Testing Geopressured Water", Department of Energy Report ORO-4937-1, issued May 1978.

2. Craig, F. F., Jr., "The Reservoir Engineering Aspects of Waterflooding," Society of Petroleum Engineers, Monograph 3, Chapter 2.

3. Frick, T. C., "Petroleum Production Handbook, Volume II, Reservoir Engineering," McGraw-Hill, 1972, p. 25-3 (rel. perm. curves), and p. 25-8 (residual saturation).

4. Dow, W. G., "Petroleum Source Beds on Continental Slopes and Rises,". 1977, AAPG Short Course.

5. Ritch, H. J., and Smith, J. T., "Evidence for Low Free Gas Saturations in Water-Bearing Bright Spot Sands," presented at SPWLA 17th Annual Symposium, June 1976 .

6. Culberson, 0.L., and McKetta, J. J., Phase Equilibria in HydrocarbonWater Systems III-The Solubility of Methane in water at Pressures to 10,000 psi, Trans AIME 192, 223 (1951).

7. Dodson, C. R., and Standing, M. B., Pressure-Volume-Temperature and Solubility Relations for Natural-Gas-Water Mixtures, Drill. and Prod. Pract., API, p. 173 (1944).

8. Flowers, B. S., "Overview of Exploration Geophysics - Recent Breakthroughs and Challenging New Problems", Bul1. AAPG 60 (Jan. 1976) 3.

9. Kennedy, H. T., and 01son, C. R., "Bubble Formation in Supersaturated Hydrocarbon Mixture," Trans AIME (1952) 195, 271.

10. Wei Tand, D. R., and Kennedy, H. T., "Measurement of Bubble Frequency in Cores," Journal of Petroleum Technology, April 1957, 122.

11. Stewart, C. R., Hunt, E. B., Jr., Schneider, F. N., Geffen, T. M., and Berry, V. J., Jr., "The Role of Bubble Formation in 0il Recovery by Solution Gas Drives in Limestone", Journal of Petroleum Technology, December 1954, p. 21, and Hunt, E. B., Jr., and Berry V. J., Jr., "Evolution of Gas from Liquids Flowing Through Porous Media," AIChE Journal (December 1956), Vol. 2, No. 4, 560.

12. Bagrodia, V., and Katz, D. L., "Gas Migration by Diffusion in Aquifer Storage, Journal of Petroleum Technology, February 1977, 121. 
13. Tissot, B., Durand, B., Espitalie, J., and Combaz, A., "Influence of Nature and Diagenesis of Organic Matter in Formation of Petroleum", Bul1, AAPG 58, No. 3, 499 (1974)

14. Hood, A., Gutjahr, C. C. M., and Heacock, R. L., "Organic Metamorphism and the Generation of Petroleum," Bu11, AAPG, 59, No. 6, 986 (1975)

15. Durand, B., and Espitalie, J., "Geochemical Studies on the Organic Matter from the Dovala Basin (Cameroon) - II, Evolution of Kerogen", Geochimica et Cosmochimeca Acta, 1976, 40, p. 801. 
APPENDIX 1

MOVEMENT OF GAS TO THE TOP OF A SAND

Under Current Conditions in Sand Number 3

In this Appendix, we will estimate the time for a non-flowing gas saturation to move to the top of a porous sand body. We will assume a sand of thickness $h$, in feet. The pressure of the liquid at the bottom of the sand is higher by approximately $0.465 \mathrm{~h}$ ps $i$ than it is at the top of the sand. This excess pressure will cause an accumulation of gas at the bottom to dissolve in the water, diffuse to the top and come out of solution there.

We can calculate the time for this movement to take place by noting that the solubility of gas produced from Delcambre No. 1 is about $18 \mathrm{SCF} / \mathrm{bbl}$. at $11,000 \mathrm{psi}$ and $238^{\circ} \mathrm{F}$ and about $17 \mathrm{SCF} / \mathrm{bbl}$. at $6000 \mathrm{psi}$ and $238^{\circ} \mathrm{F}$ (see Figure 16 ). Thus, the gradient in saturation due to pressure is $1 \mathrm{SCF} / \mathrm{bbl}$. per $5000 \mathrm{psi}$.

The effective diffusion coefficient for methane in a porous rock is about $3 \times 10^{-4} \mathrm{~cm}^{2} / \mathrm{sec}$. (see reference 12 ), or $10 \mathrm{ft} .2 / \mathrm{yr}$. The saturation difference between bottom and top is $(1 / 5.615)(.465 \mathrm{~h} / 5000)$. This is $1.66 \times 10^{-5} \mathrm{SCF}$ methane/CF water - $\mathrm{ft}$. The rate of diffusion from top to bottom under steady state conditions is rate $=(10) 1.66 \times 10^{-5}=1.7 \mathrm{X}$ $10^{-4} \mathrm{SCF} / \mathrm{Ft} .^{2}-\mathrm{Yr}$.

If the residual gas saturation is $20 \%$, the volume of gas in a cubic ft. of $30 \%$ porosity reservoir rock at 11,000 psi and $238^{\circ} \mathrm{F}$ is approximately $0.3(.2) \times \frac{11,000}{14.7} \times \frac{520}{698}=34 \mathrm{SCF} / \mathrm{CF}$. The time for the gas in the lowest $\mathrm{ft}$. (in a $30^{\prime}$ thickness of this gas) to move up to the top of the sand is $t=\frac{34(30)}{1.7 \times 10^{-4}}=6 \times 10^{6} \mathrm{yrs}$. on 6 million years.

The time required for the gas in the first $\mathrm{ft}$. of sand at the top to dissolve and reach the top is $34 / 1.7 \times 10^{-4}=200,000$ years. Thus under current conditions any gas saturation will dissipate slowly. 
Under Prior Conditions in Sand Number 3

Let us consider the hypothetical situation when sand number 3 was at a depth of about $7000^{\prime}$ and was not yet geopressured. If a free gas saturation were in that sand, how long would it have taken to have dissipated?

To estimate the time, we use the same procedure as above. We note that the change in gas solubility ${ }^{6}$ at $3500 \mathrm{psi}$ and $170^{\circ} \mathrm{F}$ is about $4 \mathrm{SCF} / \mathrm{bbl}$. for a change in pressure of $1000 \mathrm{psi}$ and a simultaneous increase in temperature of $30^{\circ} \mathrm{F}\left(1.5^{\circ} \mathrm{F} / \mathrm{ft}.\right)$. This is some 20 times as large as the gradient calculated above under current conditions. For the same diffusion coefficient, the times of gas dissipation will be 20 times faster or 10,000 years for the top $\mathrm{ft}$. in a $30^{\prime}$ sand and 300,000 years for the bottom $\mathrm{ft}$. 
APPENDIX 2

GAS/WATER PRODUCTION RATIO DURING FLOW TESTS

SAND NO. 1

The gas/water production ratio during the flow test of sand no. 1 is shown in Figure 18. At low water production rates (up to $3,000 \mathrm{~B} / \mathrm{D}$ ), the gas/water ratio is approximately equal to the solution ratio of $18 \mathrm{cu}$. $\mathrm{ft.} / \mathrm{bbl}$. As the water rate is increased from 3,000 to $12,000 \mathrm{~B} / \mathrm{D}$ the gas/ water ratio rises from approximately solution ratio ( $18 \mathrm{cu}$. ft./bbl.) to about $55 \mathrm{cu}$. ft./bbl.

This behavior is consistent with the behavior of a water sand with an updip gas cap, such as that shown in Figure 1. A schematic crosssection of possible behavior during the flow test is sketched below.
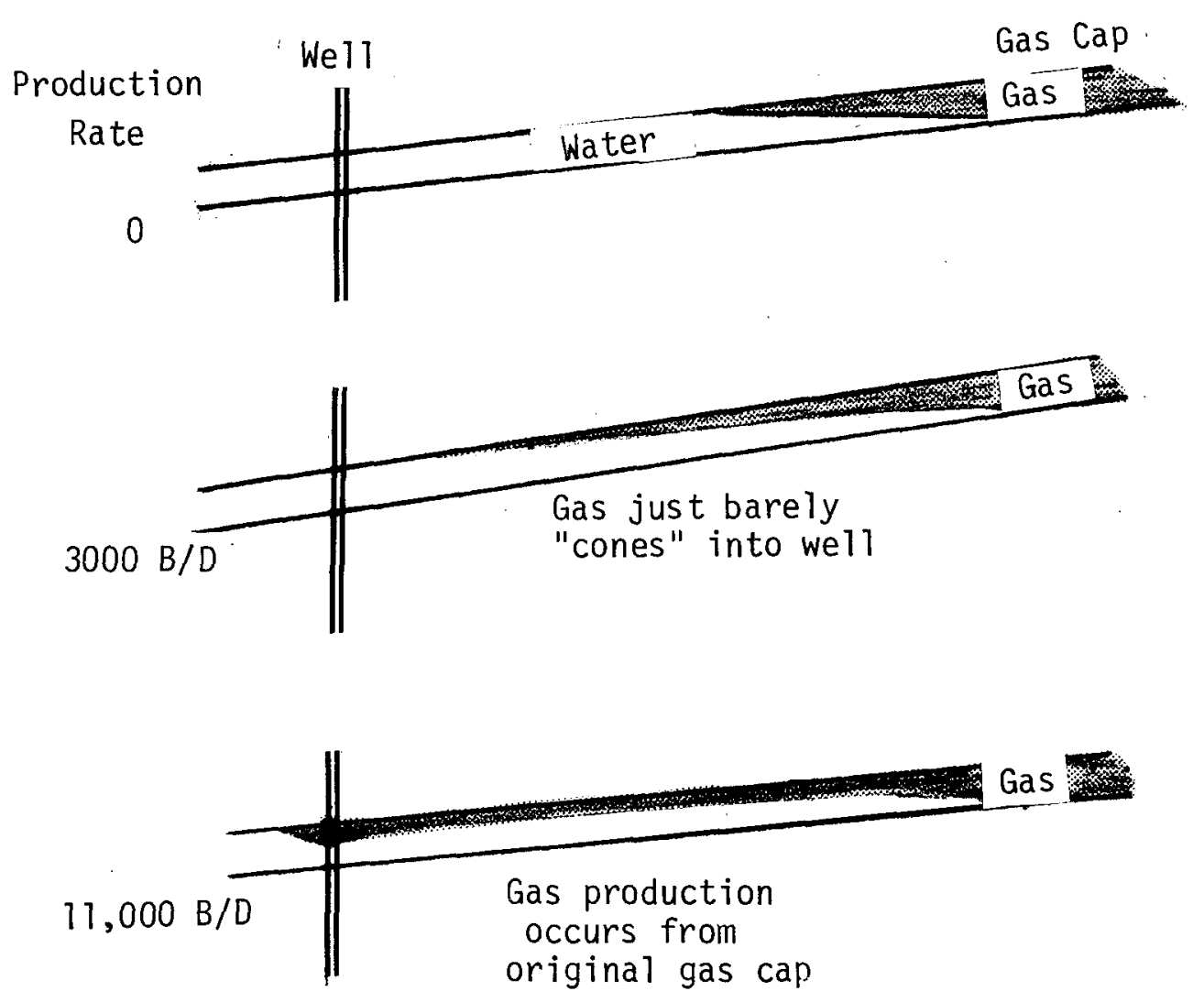

* See footnote, page 15. 
The plot of gas/water production ratio versus cumulative water production (Figure 19) is also consistent with "coning down" of gas. Before the updip gas can be produced, some of the intervening water must first be produced. Thus we would expect that at early times (10w cumulative water production) the gas/water ratio would be low. After the "cone" reached the well the gas/water ratio would rise. This is what happened in the test of sand no. 1. After some water was produced at the gas/water solution ratio, this ratio rose in steps as the production rate increased in steps.

SAND NO. 3

The gas/water production rate during the production test of sand no. 3 is shown in Figure 20. The behavior is entirely different from that of sand no. 1. For low water production rates, the gas/water production ratio is high. As the water production rate increased, the gas/water ratio decreased.

One possible explanation for this behavior is that better perforation was obtained opposite the gassy interval $\left(12,873^{\prime}-12,876^{\prime}\right.$ on Figure 2) than opposite the water interval $\left(12,876^{\prime}-12,911^{\prime}\right)$. This is shown schematically below.

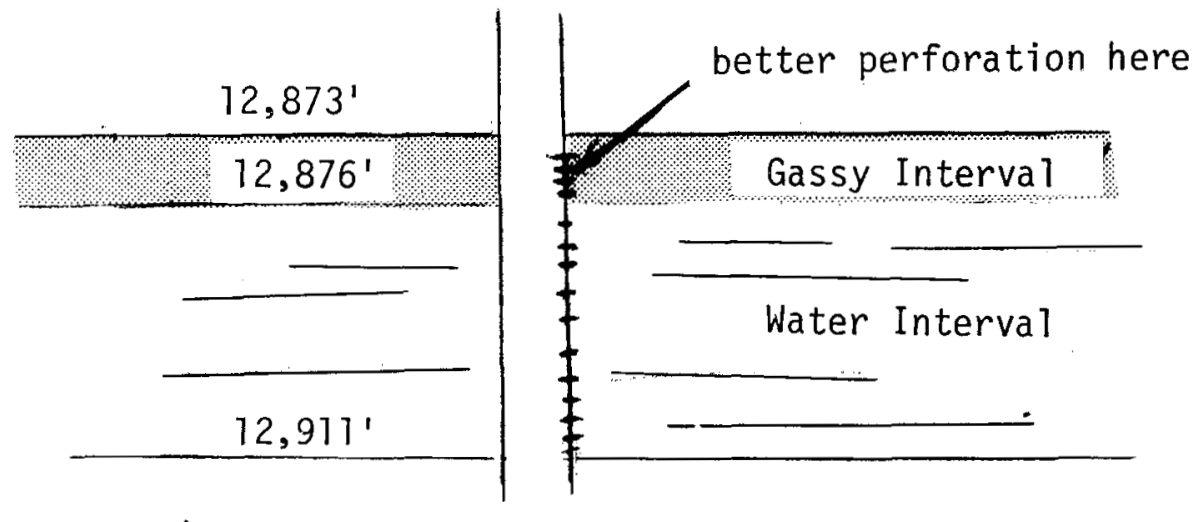

If the well was perforated better in the gassy interval than in the water interval, the gas would flow into the well relatively more easily than the water. As the pressure was decreased in the production well by opening the choke at the surface, the water could "cone upward" into the gas zone perforations, thereby decreasing the gas/water ratio. The early difficulty with getting good perforation in the no. 3 sand lends some credence to this hypothesis. The well was first perforated and then reperforated in the upper interval $\left(12,869^{\prime}-12,893^{\prime}\right)$. This may have led to a better connection with the gassy interval than with the water interval below it. 
In Figure 20, the numbers at each plotted point refer to the order in which each flow rate was taken during the test. Thus, point 1 was taken first, point 2 second, etc. One of the higher gas/oil ratios was point 8, taken near the end of the production test. However, this was a low rate test, conducted with high well backpressure (see Flow Data on Sand No. 3). Thus, less water would be "coned" up and the gas/water ratio should have been higher, by our hypothes is of better perforation in the gassy interval. The fact that all points on Figure $20 \mathrm{fit}$ the curve of gas/water ratio versus rate reasonably well, regardless of order in which taken lends credence to this hypothesis. 
APPENDIX 3

SOURCE OF GAS FOUND IN THE LOUISIANA MIOCENE

References 4, 13, 14 and 15 contain we 11 documented studies of petroleum source beds. A brief summary of latest findings is given below.

\section{ORIGIN OF PETROLEUM}

Many studies have shown that most commercial hydrocarbons are generated by thermal transformation of buried organic matter which was originally deposited under reducing conditions. The organic matter is generally found in marine clays. As the clays are buried they are altered and becomes shales and, simultaneously, the organic matter is converted to petroleum.

Evidence for this transformation of organic matter is obtained by sampling sediments as a function of depth, extracting the organic matter, and analyzing it. In young sediments little hydrocarbon is found with the exception of methane of biochemical origin (marsh gas). The very small amount of hydrocarbons which do occur typically have distributions of $n$ alkanes with a higher number of odd carbon carbons than of even. This reflects the ratio of their precursors in living plants. This odd/even predominance does not occur in petroleum. The smooth distribution of hydrocarbons in petroleum is evidence that petroleum is a thermal transformation product of heavy organic material. The heavier organic molecules when heated do give a smooth distribution of hydrocarbons.

Other evidence for transformation of heavy organic material to petroleum as a function of temperature and time has been obtained by analyzing for oxygen, which is present in the organic molecules at shallow depths. The analyses show first of a11 progressive elimination of the $C=0$ group with depth of burial. At still greater depth, hydrogen is eliminated.

Along with this transformation, a coal-like mineral, vitrinite, found with the organic matter, undergoes an increase in reflectance. Vitrinite reflectance has been found to be an accurate mirror of the amount of transformation to petroleum.

\section{DEPTH OF GENERATION}

Both time and temperature are involved in this transformation of organic matter to petroleum. $0 i 1$ is generated at the shallowest depths. At greater depths wet gas is generated. Finally, at still greater depths dry 
gas is formed. These relations are shown in Figure 21 , along with various scales which indicate maturity of petroleum generation. Dry gas is not formed until the vitrinite reflectance (the most widely used scale) reaches 1.0 .

\section{THE MIOCENE OF LOUISIANA}

The Miocene formation of Louisiana has been deposited relatively rapidly. Figure 22 shows vitrinite reflectance as a function of depth. Note that a depth of about $19,000^{\prime}$ and a temperature of $340^{\circ} \mathrm{F}$ is required to give a vitrinite reflectance of 1.0 for middle Miocene, the formation of interest in our tests of Delcambre \#1. Thus dry gas would not be generated in middle Miocene sediments until it reached a depth of about $19,000^{\prime}$ and a temperature of $340^{\circ} \mathrm{F}$. The 12,000' depth at which we tested the number one and the number three sands is definitely too shallow for dry gas generation.

We conclude that the source of the dry gas seen in Delcambre \#1 must be the much deeper sediments of 19,000'+. 


\begin{tabular}{|c|c|c|c|c|c|c|c|c|c|}
\hline \multicolumn{10}{|c|}{ FLOW DATA Sd\#I } \\
\hline $\begin{array}{l}\text { CHOKE } \\
\text { SIZE }\end{array}$ & \begin{tabular}{|} 
DURATION OF \\
FLOWTEST
\end{tabular} & \begin{tabular}{|c|} 
MINIMUM PSIA \\
BOT TOM \\
HOLE PRESS \\
\end{tabular} & \begin{tabular}{|l|} 
MIN. SURF. \\
PRESS.PSIG \\
\end{tabular} & \begin{tabular}{|c||} 
MAX. SURF. \\
TEMP. OF \\
\end{tabular} & \begin{tabular}{|c|} 
WATER AVG. \\
BBL/DAY \\
\end{tabular} & \begin{tabular}{|c|} 
TTL. $Q_{\text {WATER }}$ \\
BBLS.
\end{tabular} & \begin{tabular}{|c}
$Q_{\text {GAS }}$ AVG. \\
MCF/D
\end{tabular} & $\begin{array}{c}\text { TTL. } Q_{G A S} \\
S C F\end{array}$ & $\frac{Q_{\text {GAS }}}{Q_{\text {WATER }}} \frac{S C F}{\text { BBL }}$ \\
\hline $10 / 64^{11}$ & 48 HRS & 10601.05 & 4790 & 148 & 1165 & 2330 & 19.61 & 39237 & 16.84 \\
\hline $14 / 64^{\prime \prime}$ & 48 HRS & 10406.68 & 4552 & 178 & 2040 & 4080 & 38.13 & 76260 & 18.6 \\
\hline $18 / 64^{i 1 \mid}$ & 48 HRS & 10215.81 & 4259 & 192 & 3146 & 6292 & 60.47 & 120940 & 19.2 \\
\hline $22 / 64^{4}$ & $48 \mathrm{HRS}$ & 10073 & 3947 & 202 & 4752 & 9504 & 130.80 & 261600 & 27.5 \\
\hline $26 / 64^{\prime \prime}$ & 39 HRS & 9905 & 3542 & 209 & 6007 & 9760 & 311 & 506532 & 51.9 \\
\hline $30 / 64^{11}$ & 20 HR 34MIN & 9835 & 3198 & 210 & 7599 & 6535 & 333.24 & 286586 & $43.8 *$ \\
\hline $34 / 64^{\prime \prime}$ & $20 \mathrm{HR} 19 \mathrm{MIN}$ & 9748 & 2883 & 215 & 8479 & 7178 & 544.4 & 460858 & 64.2 \\
\hline $38 / 64^{\prime \prime}$ & 18 HR 26MIN & 9688 & 2394 & 219 & 9691 & 7744 & 613.1 & 470912 & 60.8 \\
\hline $42 / 64^{\prime \prime}$ & $4 \mathrm{HR} \quad 18 \mathrm{MIN}$ & 工 & 2135 & 215 & 11399 & 2057 & 550.27 & 98590 & 47.9 \\
\hline $46 / 64^{\prime \prime}$ & 7HR I 8MIN. & & 1798 & 222 & 12339 & 3753 & 765.09 & $\mid 232715$ & $6 \cdot 2$ \\
\hline $46 / 64^{\prime \prime}$ & MAX.RATE C & ONDITIONS & 1798 & 222 & 12653 & 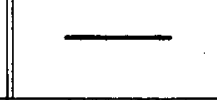 & 710.83 & - & 56.17 \\
\hline
\end{tabular}




\begin{tabular}{|c|c|c|c|c|c|c|c|c|c|}
\hline $\begin{array}{l}\text { CHOKE } \\
\text { SIZE }\end{array}$ & $\begin{array}{l}\text { DURATION OF } \\
\text { FLOWTEST }\end{array}$ & $\begin{array}{c}\text { MINIMUM } \\
\text { BOTTOM HOLE } \\
\text { PRESS. PSIA }\end{array}$ & $\begin{array}{l}\text { MIN. SURF. } \\
\text { PRESS. PSIG }\end{array}$ & $\begin{array}{l}\text { MAX. SURF. } \\
\text { TEMP. OF }\end{array}$ & $\begin{array}{l}Q_{\text {WATER }} \text { AVG } \\
\text { BBL/DAY }\end{array}$ & $\begin{array}{l}\text { TTL. } Q_{\text {WATER }} \\
\text { BBLS }\end{array}$ & $\begin{array}{l}Q_{G A S} A V G \\
M C F / D\end{array}$ & $\begin{array}{l}\text { TTL Q Q GAS } \\
\text { SCF }\end{array}$ & $\frac{Q_{\text {GAS }}}{Q_{\text {WATER }}} \frac{S C F}{B B L}$ \\
\hline $\begin{array}{l}\text { FLARED } \\
\text { TO PIT }\end{array}$ & 18 HRS - & $\longrightarrow$ & 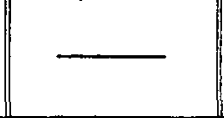 & 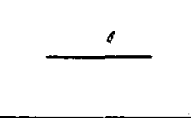 & 2608 & $\begin{array}{c}1956 \\
\text { (ESTIMATE) }\end{array}$ & 573.3 & $\begin{array}{c}430000 \\
\text { (ESTIMATE) }\end{array}$ & 219.84 \\
\hline $20 / 64^{\prime \prime}$ & $25 \mathrm{HR} \quad 30 \mathrm{MIN}$ & 10721 & 3255 & 184 & 2602 & 2765 & 578.8 & 615000 & 222.42 \\
\hline $30 / 64^{\prime \prime}$ & $24 H R$ & 8439 & 2130 & 211 & 5460 & 5460 & 309 & 309000 & 56.59 \\
\hline $40 / 64^{4}$ & $3 \mathrm{HR}$ & 8789 & 1719 & 219 & 8328 & 1041 & 352 & 44000 & 42.27 \\
\hline $40 / 64^{\prime \prime}$ & * $14 \mathrm{HR}$ & 8851 & 1723 & 219 & 8628 & 5033 & 529.7 & 309000 & 61.39 \\
\hline $20 / 64^{11}$ & $32.5 \mathrm{HR}$ & & 4124 & 195 & 3738.8 & 5063 & 214.9 & 291000 & 57.48 \\
\hline $22 / 64^{\prime \prime}$ & $1.5 \mathrm{HR}$ & & 3662 & 190 & 5744 & 359 & 304 & 19000 & 52.92 \\
\hline $18 / 64^{\prime \prime}$ & $94 \mathrm{HR}$ & 10232 & 4307 & 192 & 3252.5 & 12739 & 236.9 & 928000 & 72.85 \\
\hline $18 / 64 "$ & *** $7.25 \mathrm{HR}$ & - & 4387 & 178 & 3343.4 & 1010 & 149 & 45000 & 44.55 \\
\hline & MAXIMUM & RATE & 1714 & 206 & 10333 & - & 260 & & 25.16 \\
\hline \multicolumn{10}{|c|}{$\begin{array}{l}\text { * PRODUCED SAND } \\
\text { * * SAND FOUND OVER I/2 OF PERFS AFTER LAST TEST }\end{array}$} \\
\hline
\end{tabular}


Cartocraft Desk Outline Map, Louisiana No.7117

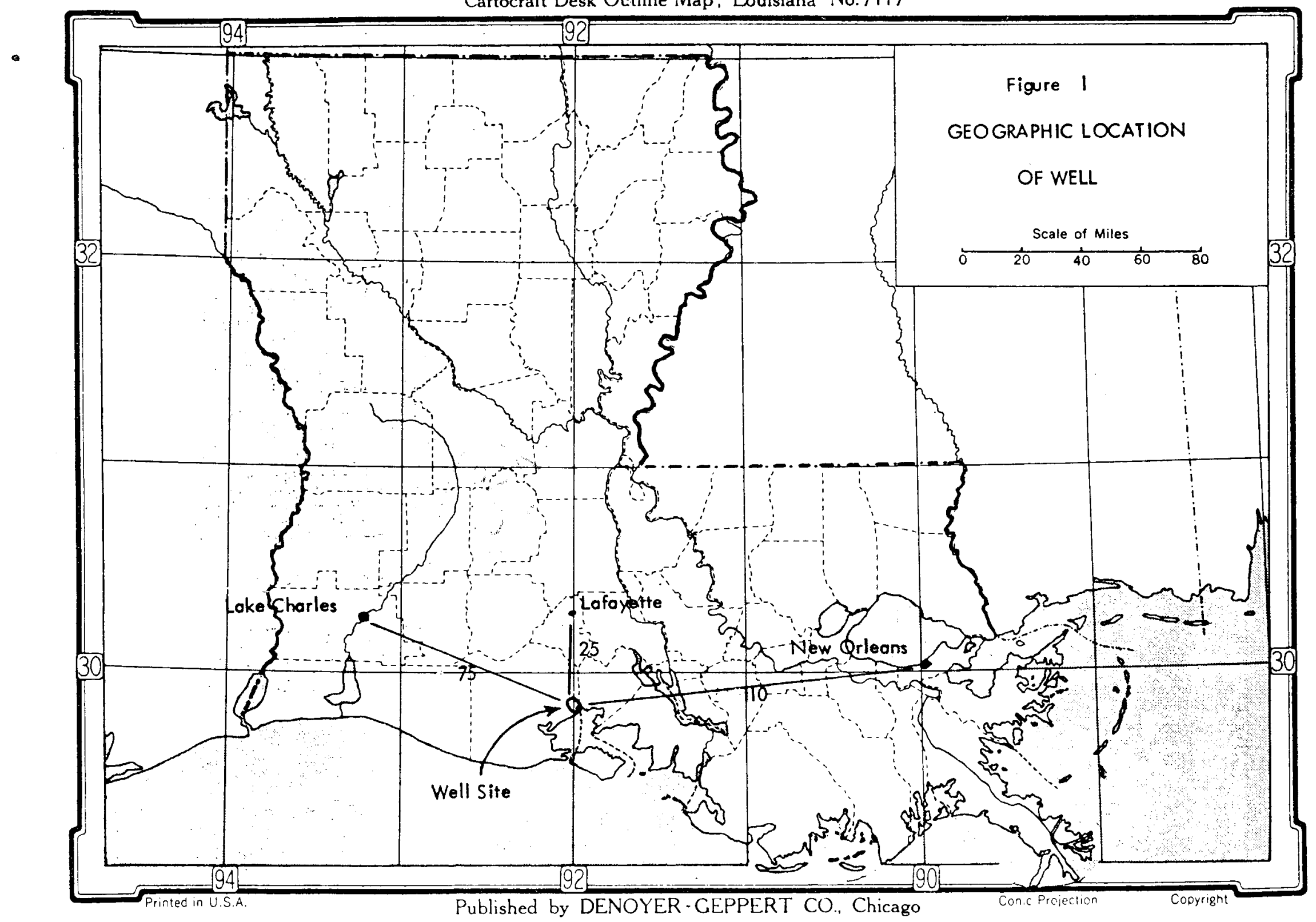


FIGURE 2

NUMBER 2 AND NUMBER 3 SANDS EDNA DELCAMBRE No. 1

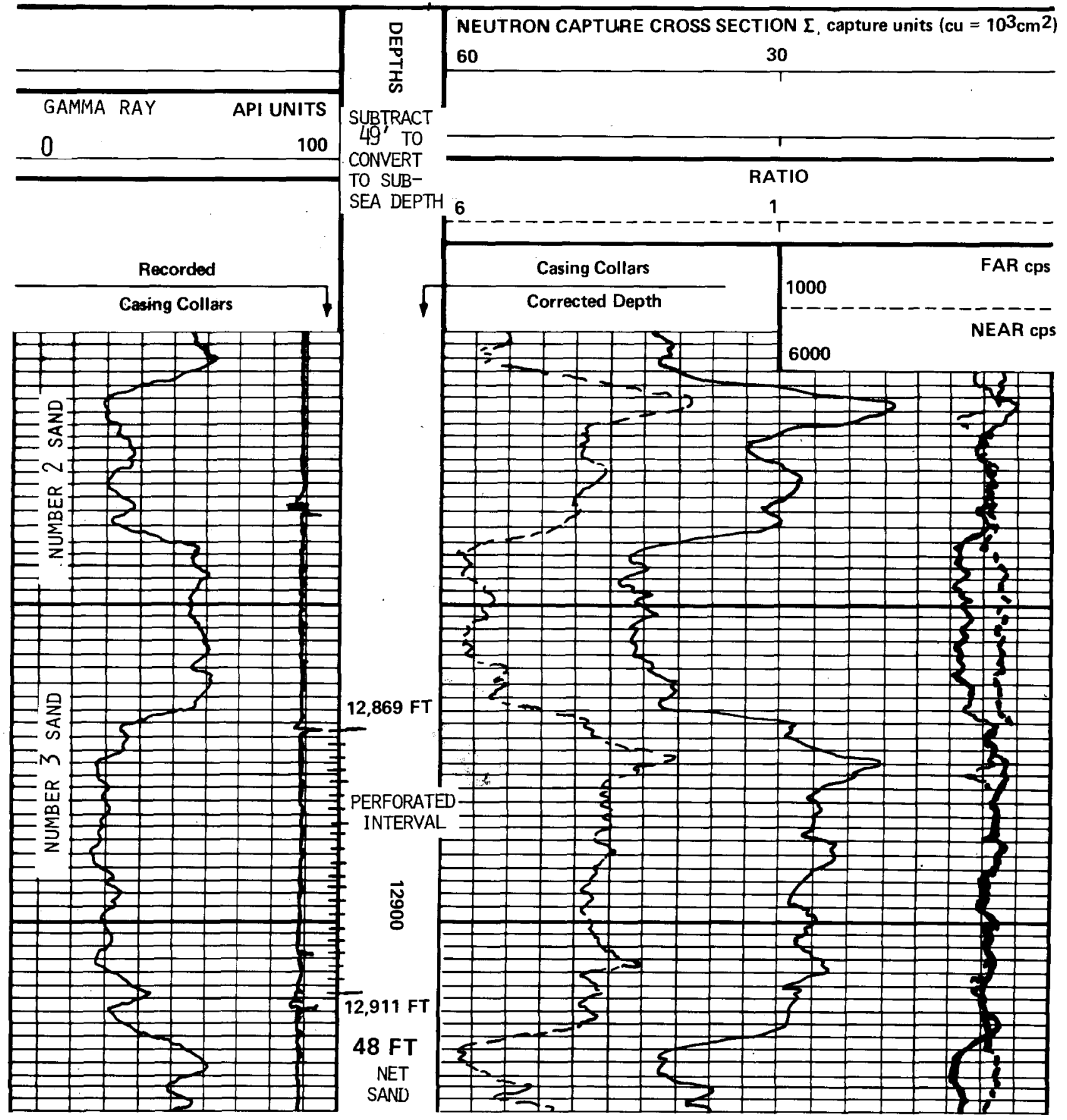


FIGURE 3

\section{NUMBER 1 SAND}

EDNA DELCAMBRE No. 1

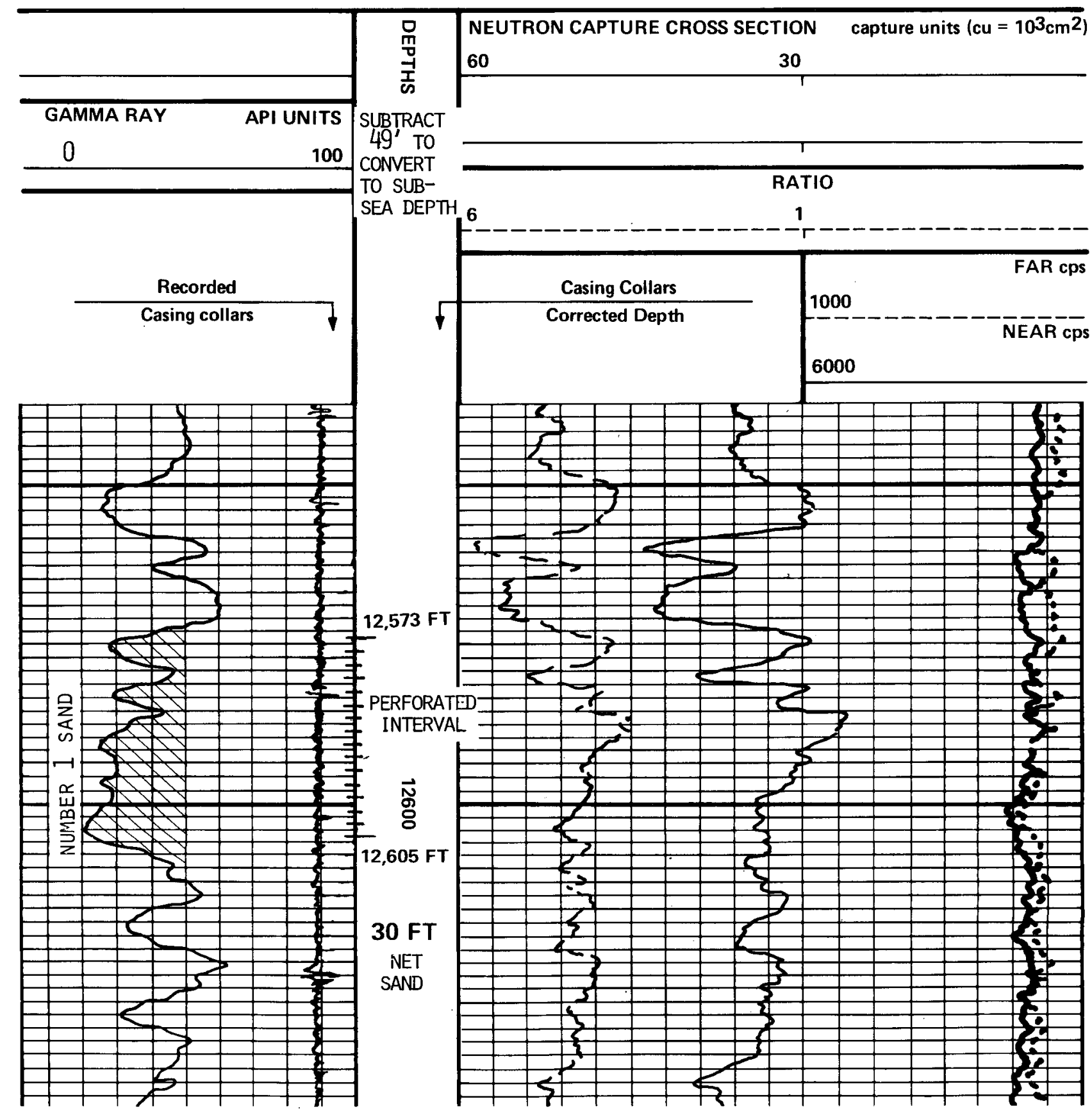




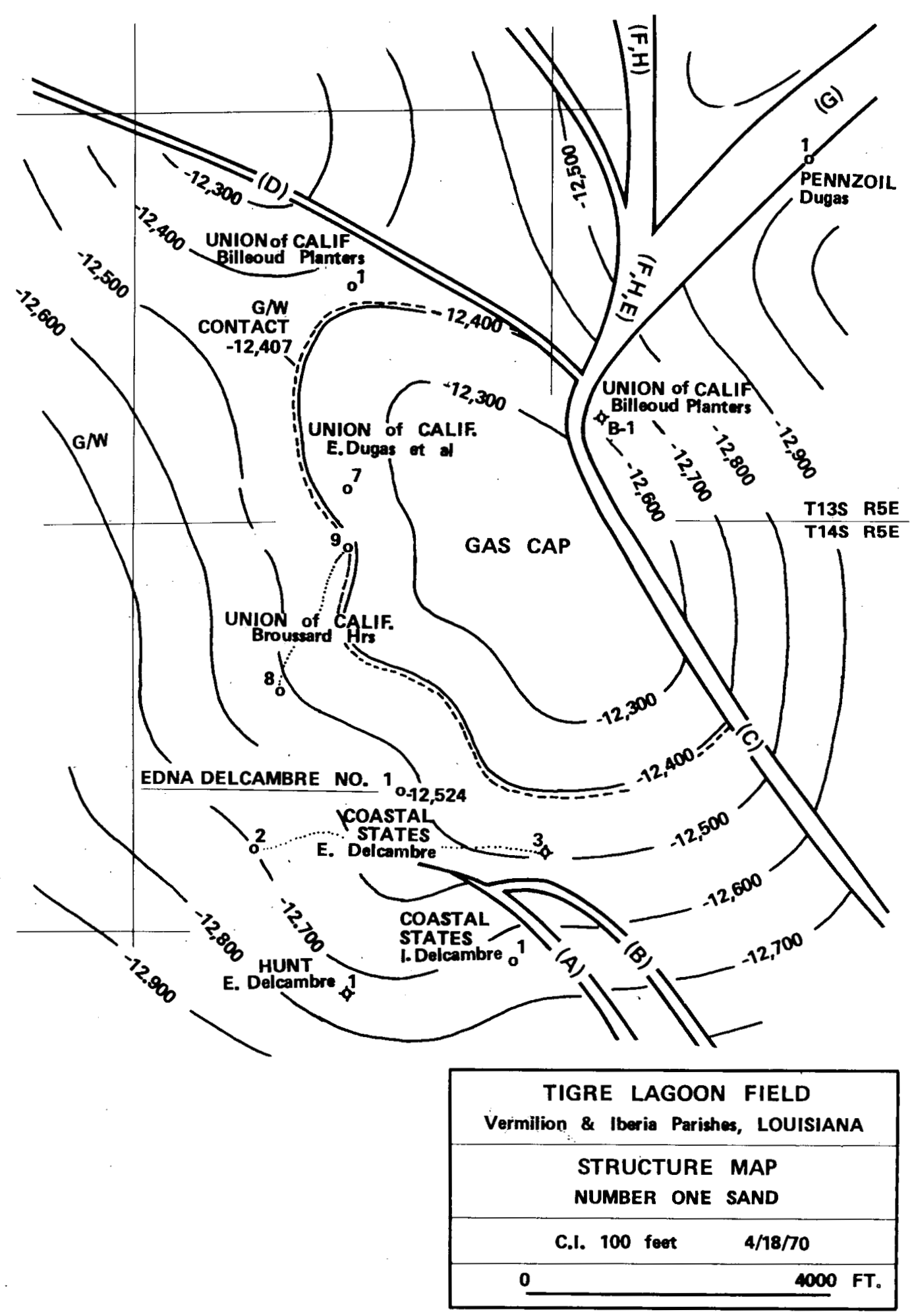


FIGURE 5

\section{A DOUBLET PORE}

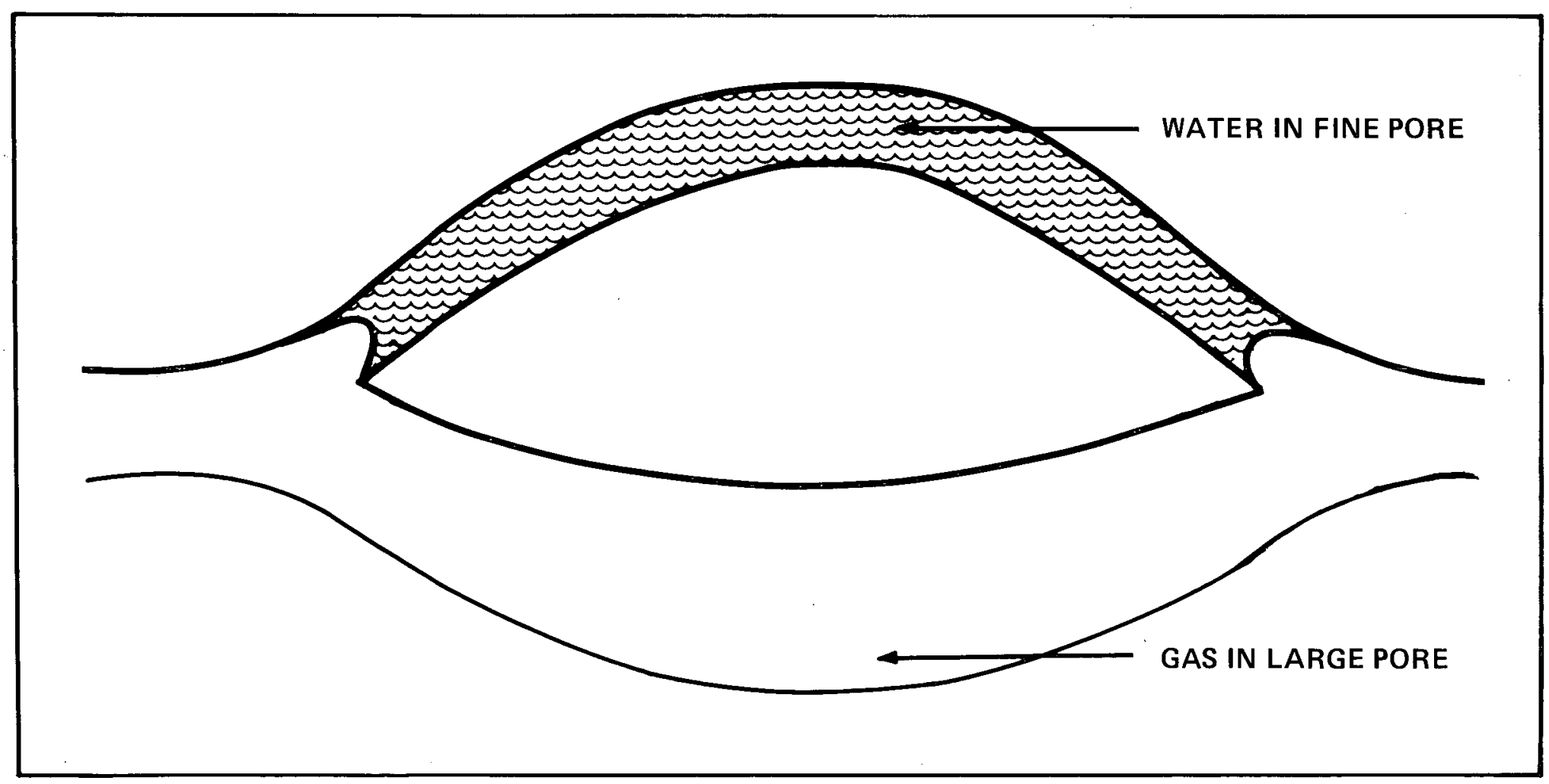


FIGURE 6

TRAPPING OF GAS BY INVADING WATER

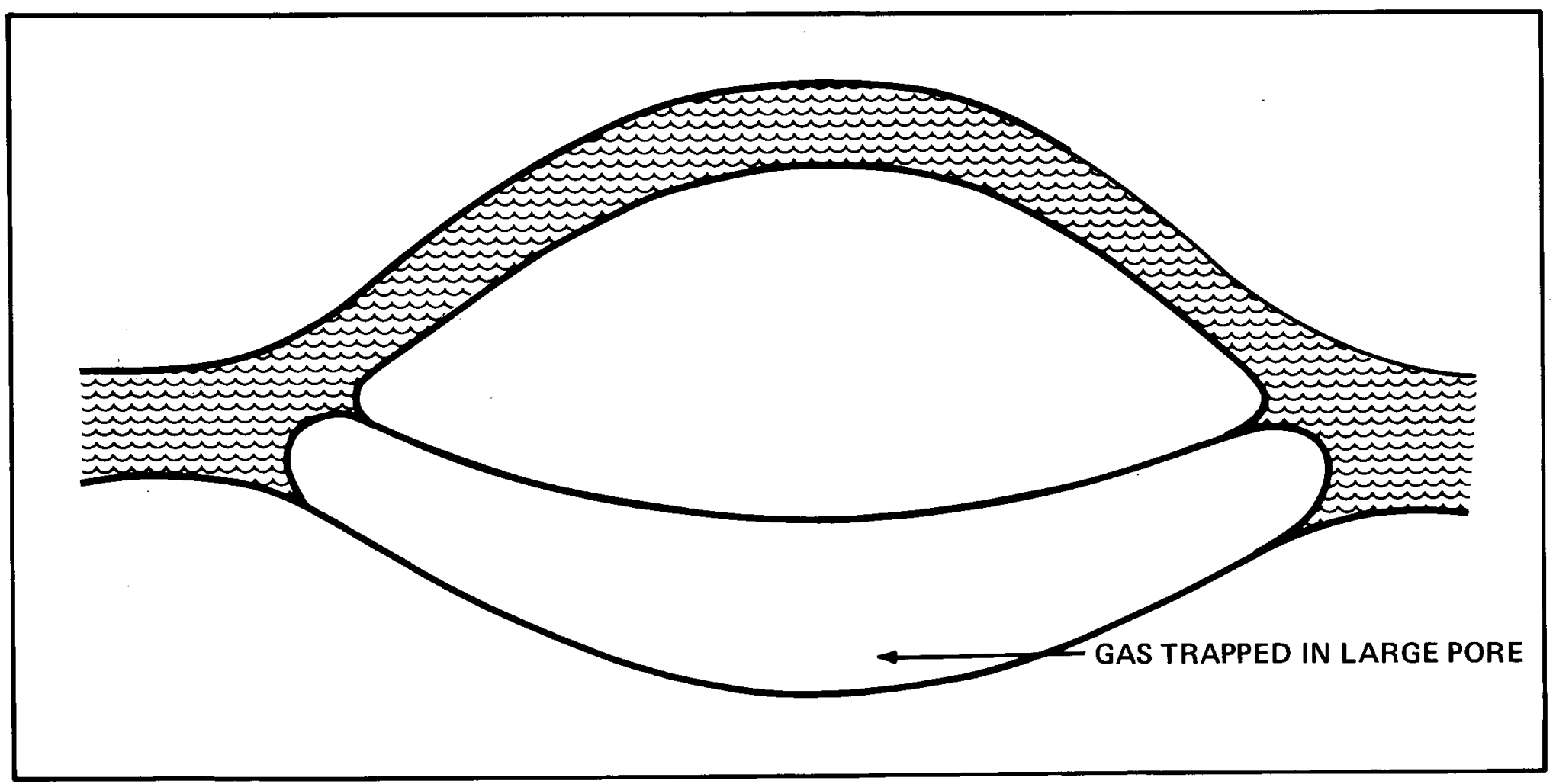




\section{GAS AND WATER RELATIVE \\ PERMEABILITY CURVES}

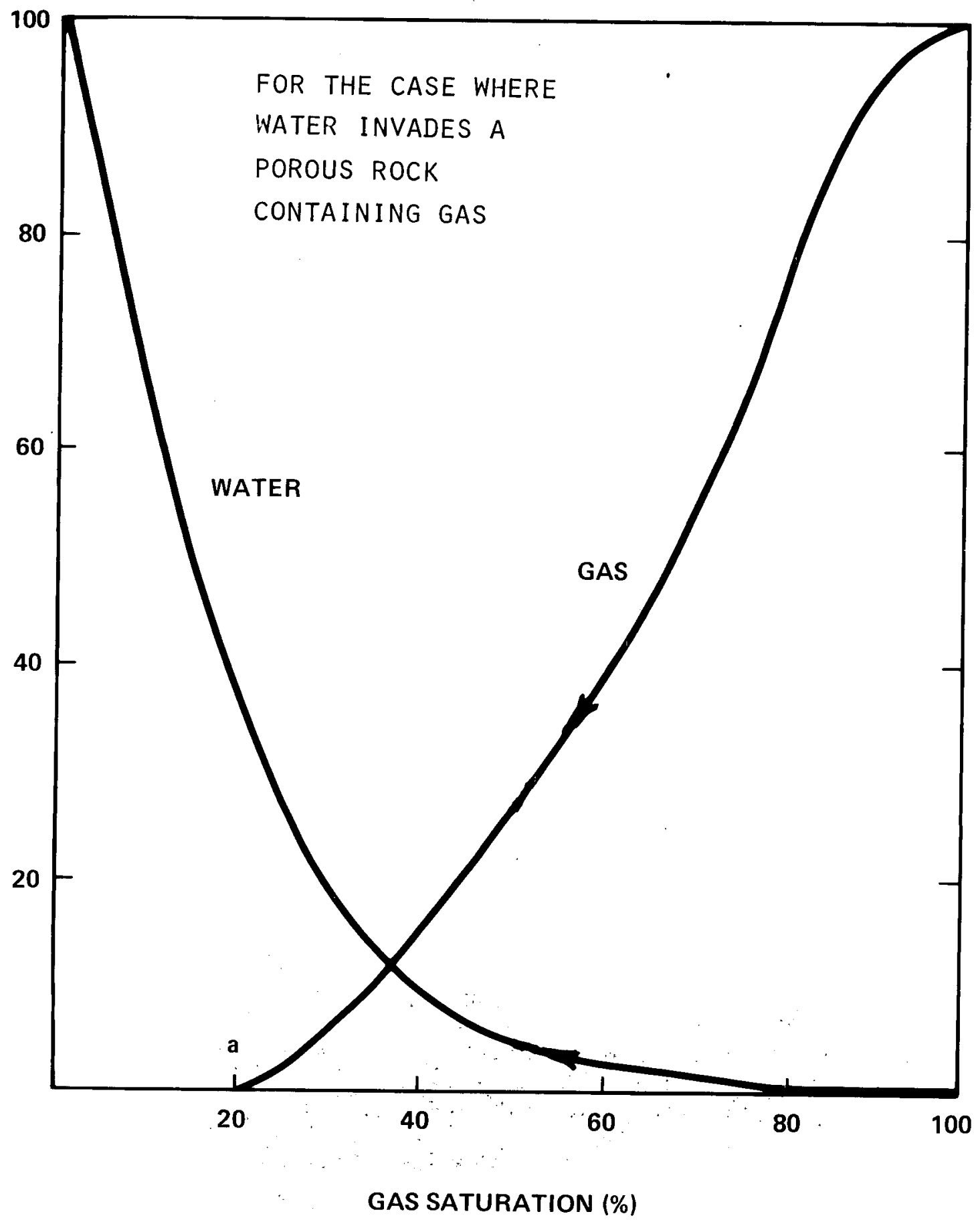

$a=$ RESIDUAL GAS SATURATION 


\section{MIGRATION OF GAS}

SURFACE OF EARTH

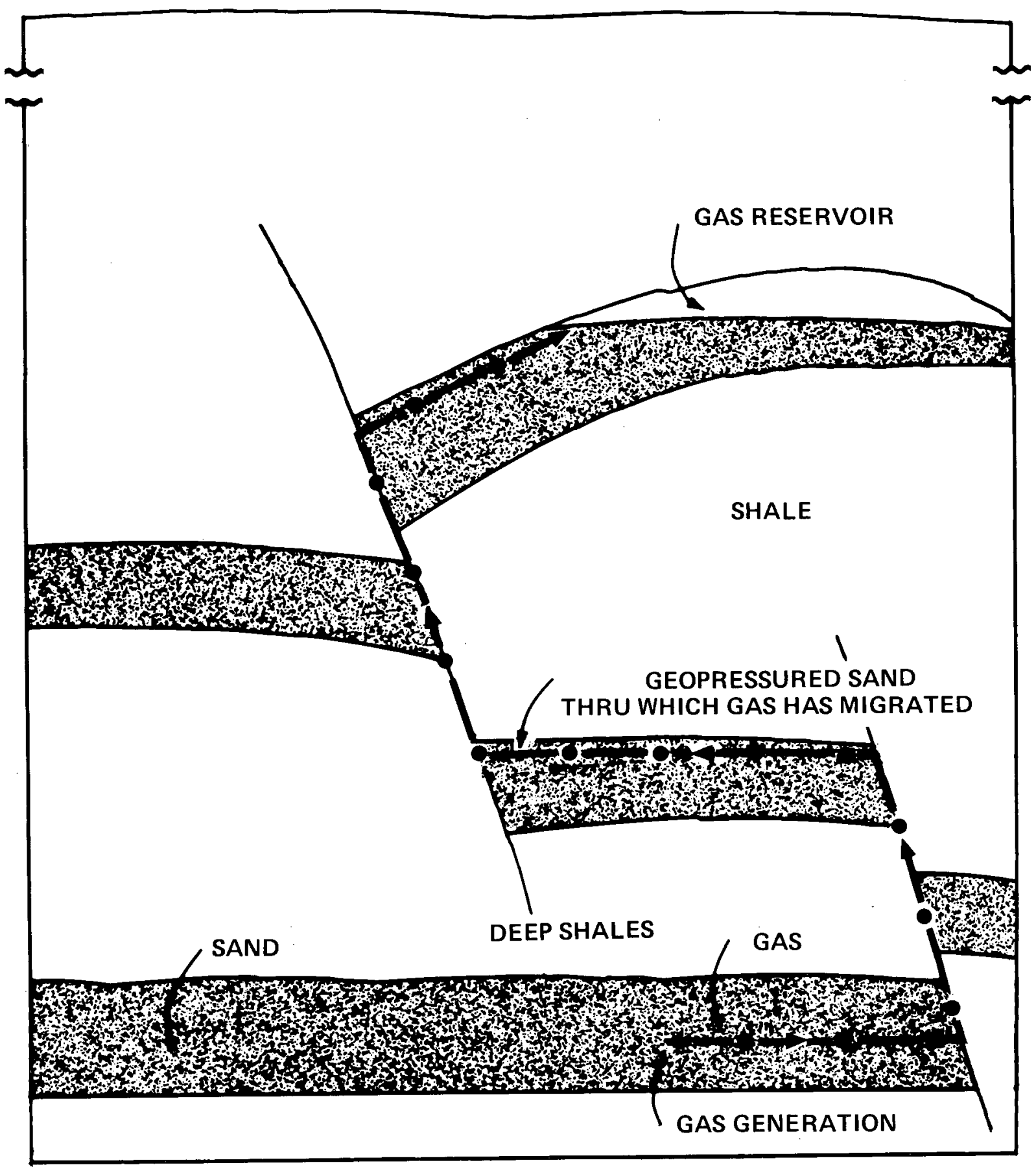


FIGURE 9

\section{GAS INVADING WATER FILLED}

PORE SPACE

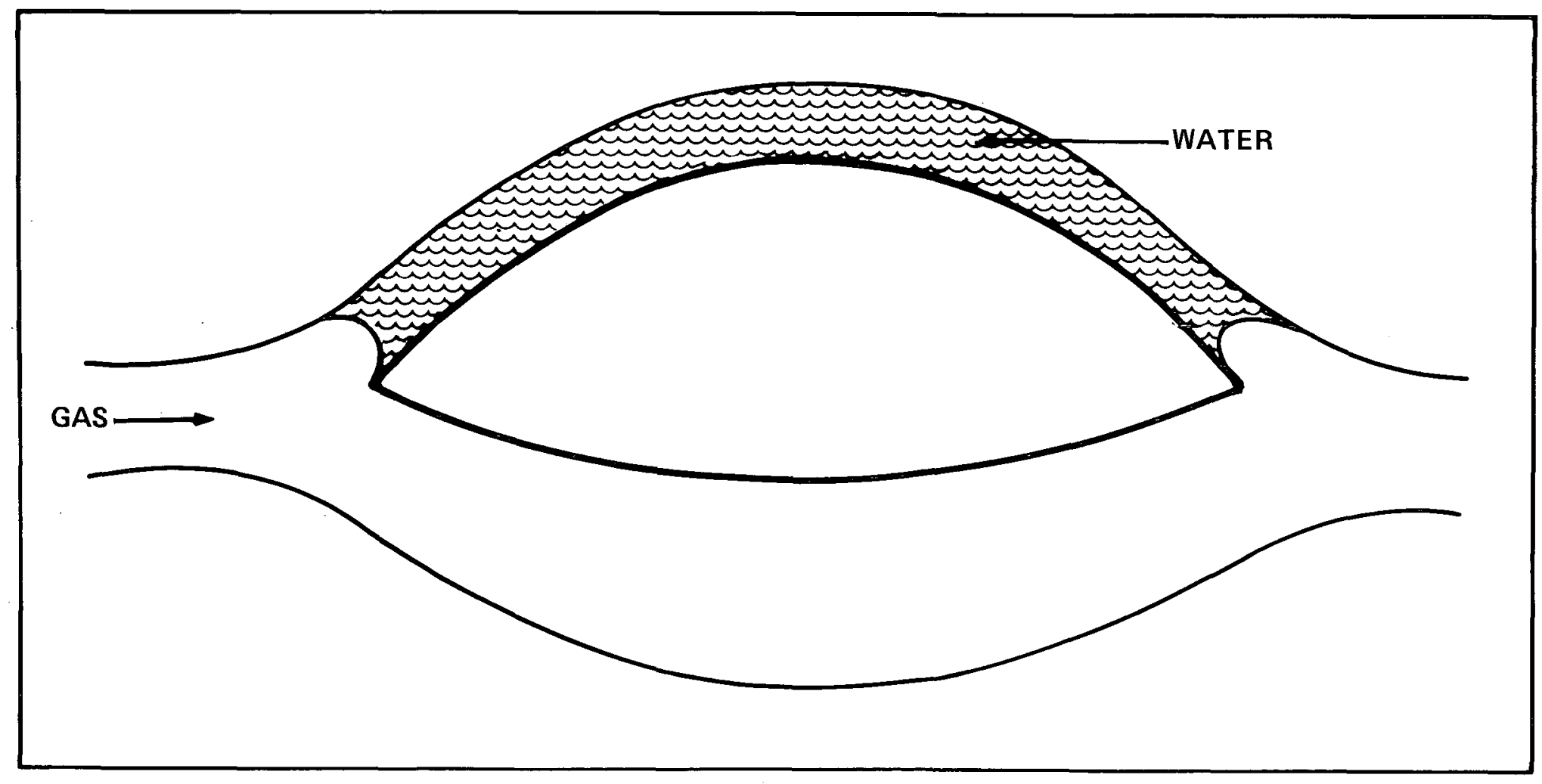

GAS HAS ESTABLISHED CONTINUITY (AND FLOW) BY INVADING ONLY THE LARGE PORES 
FIGURE 10

\section{GAS AND WATER RELATIVE \\ PERMEABILITY CURVES}

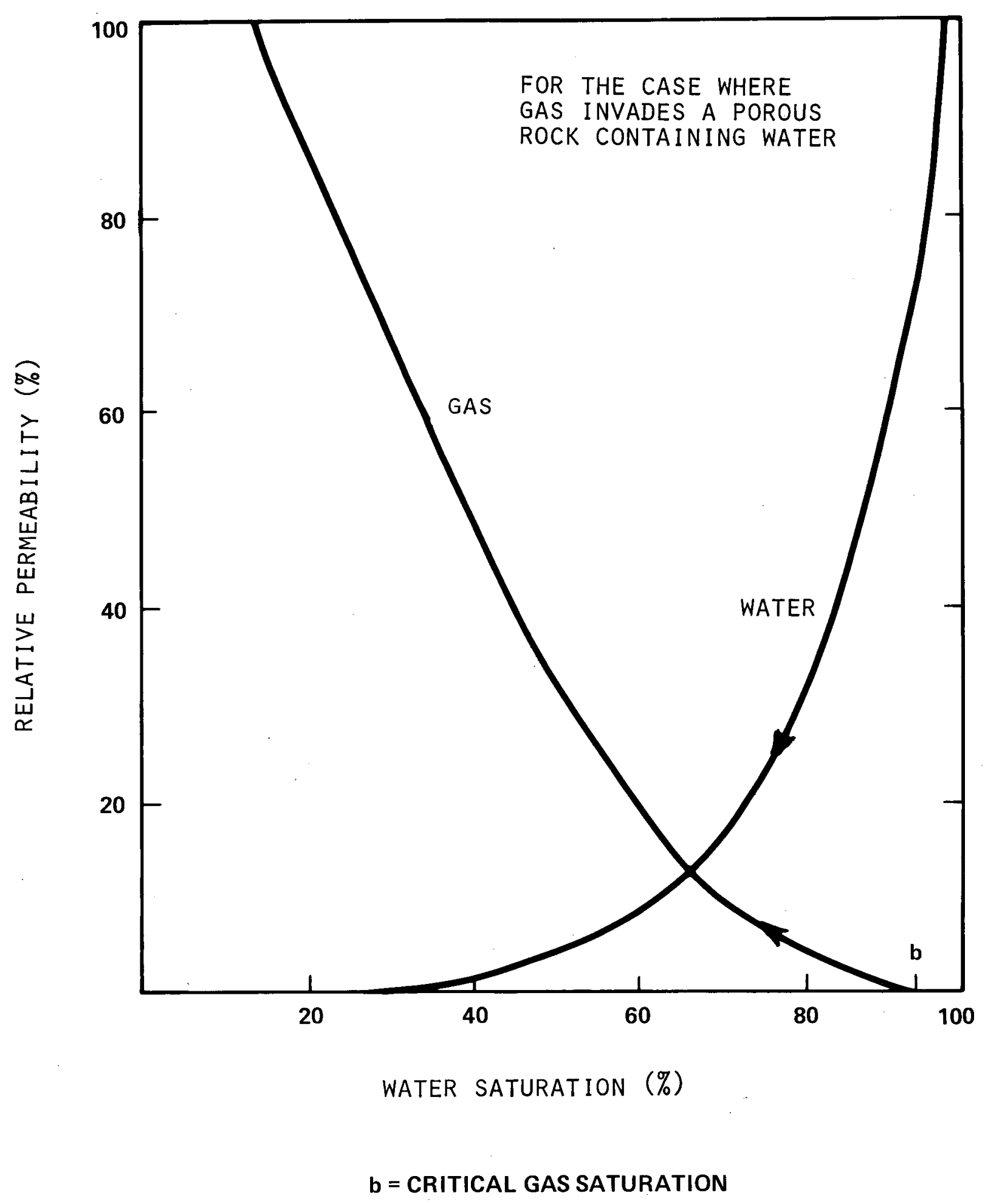


FIGURE 11

CAPILLARY PRESSURE

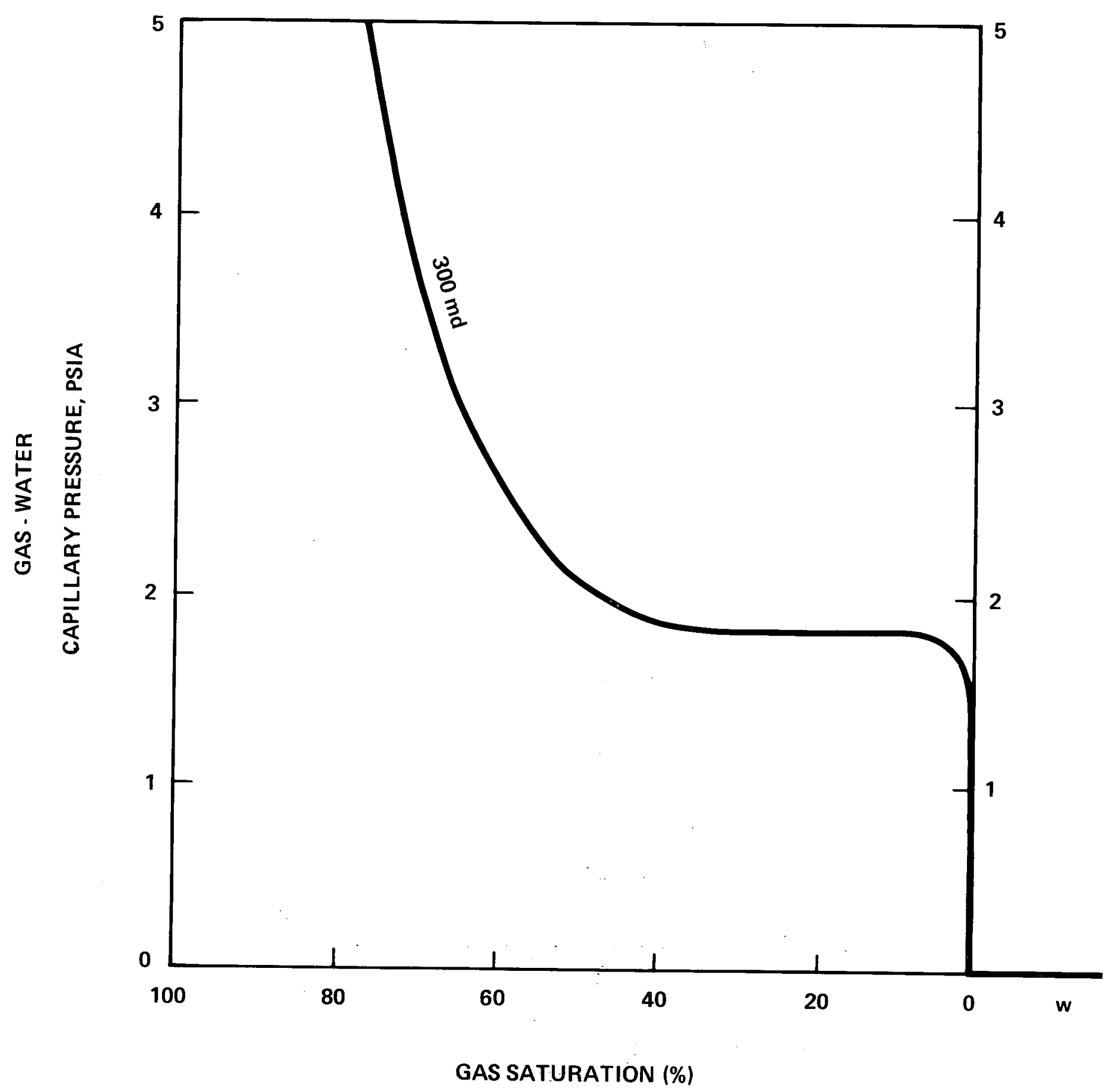

(FROM FRICK, 23-31) 


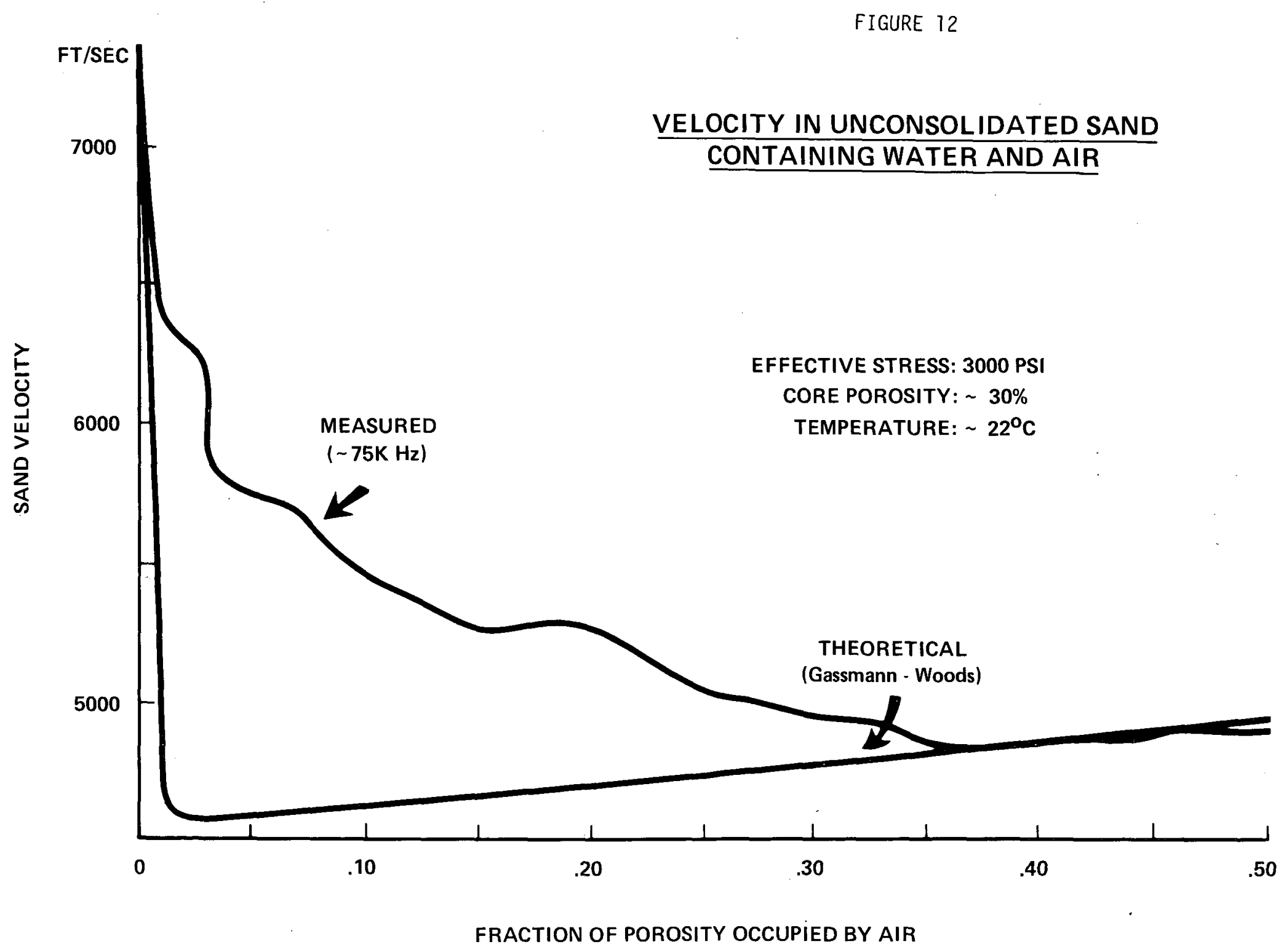


FIGURE 13

SONIC LOC

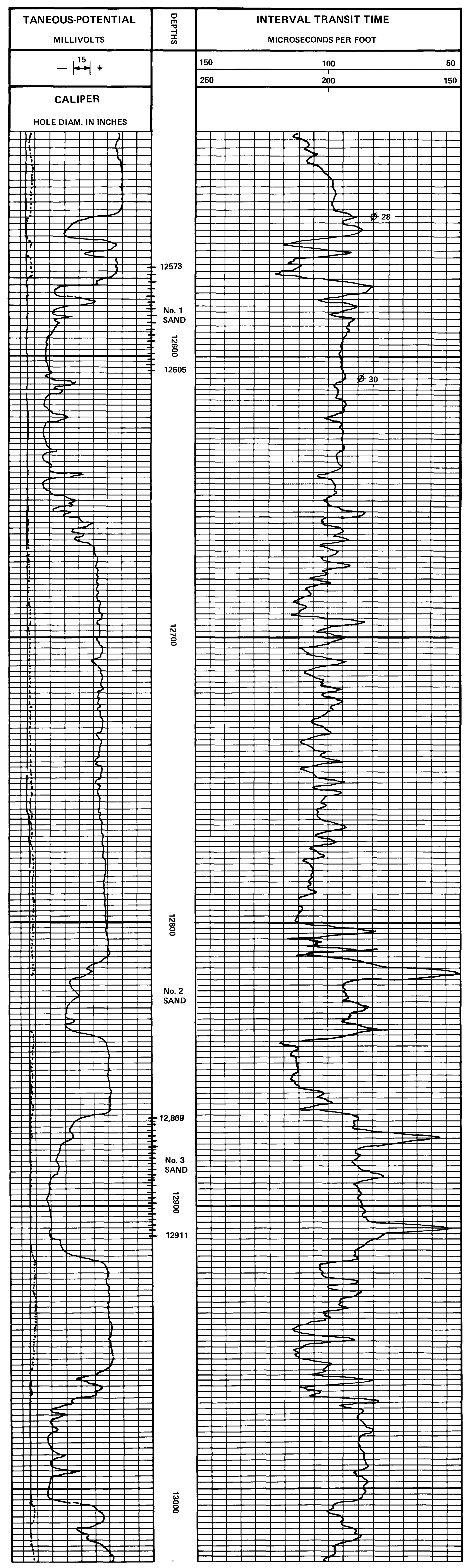


FIGURE 14

\section{GAS BUBBLE IN A}

DOUBLET PORE

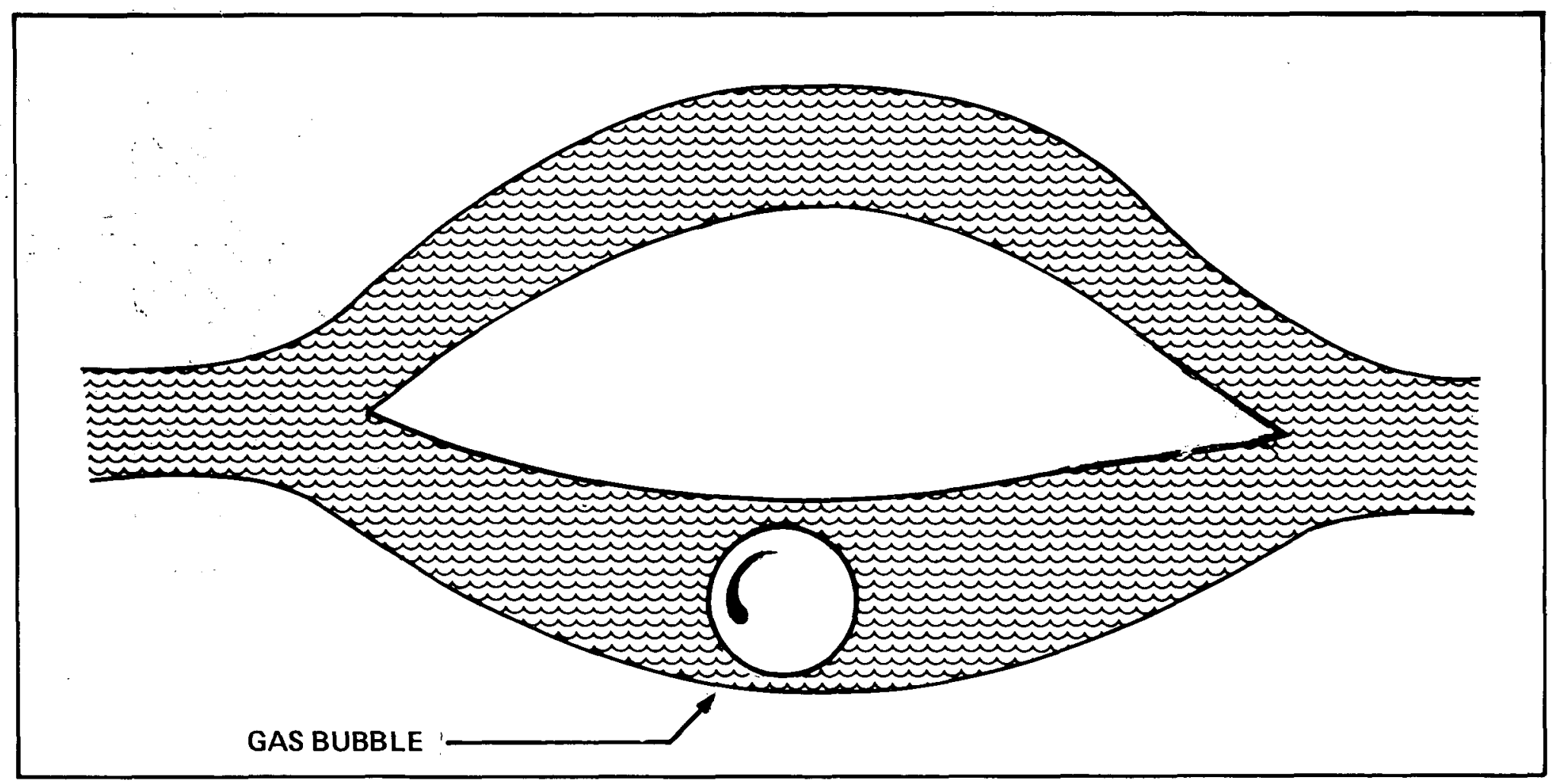




\section{PRESSURE DISTRIBUTION DURING FLOW}

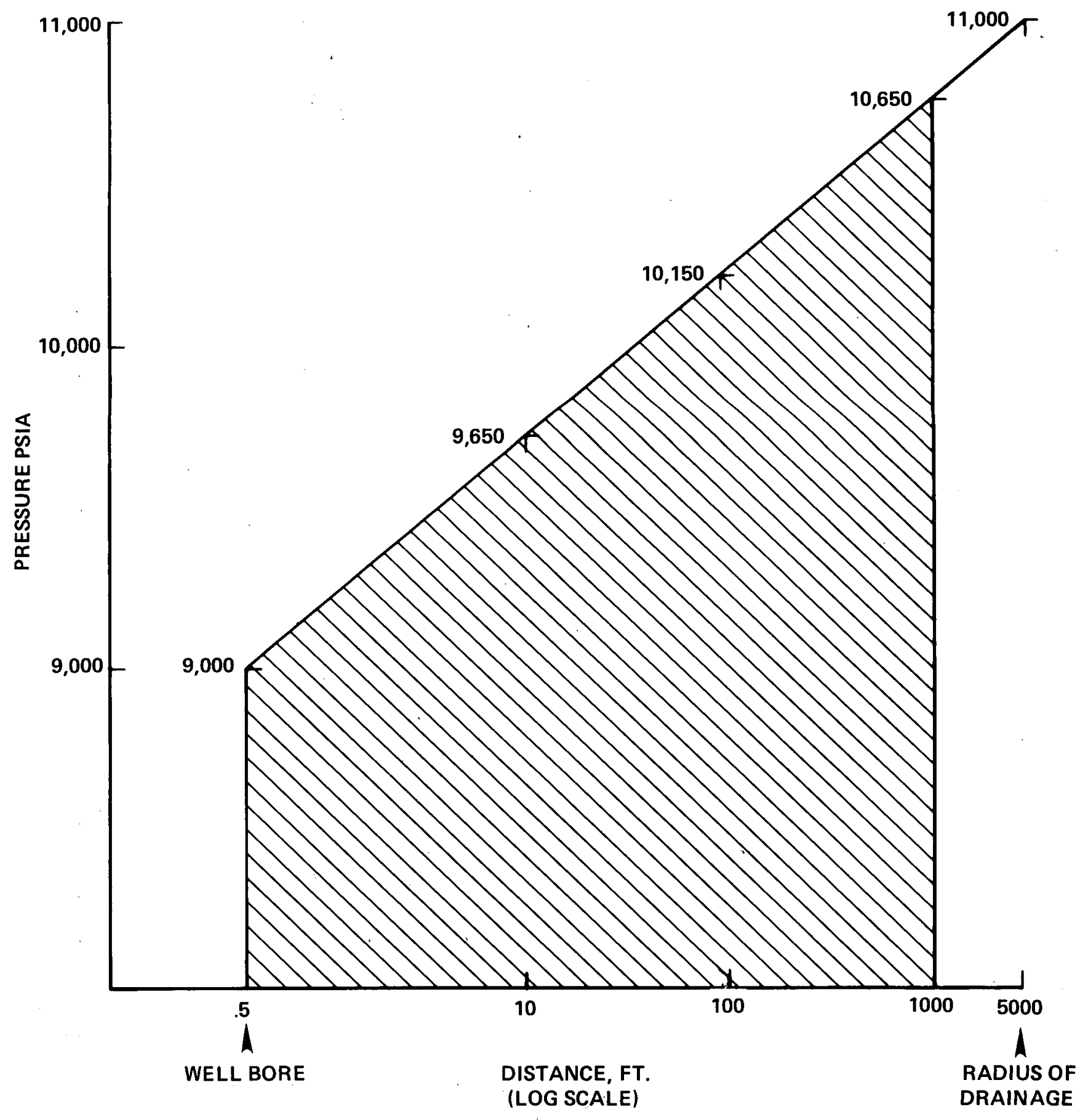

ONLY 4\% OF RESERVOIR VOLUME IS IN HATCHED AREA; 


\section{SOLUBILITY OF GAS AND WATER}

PRODUCED FROM NO. 3 SAND

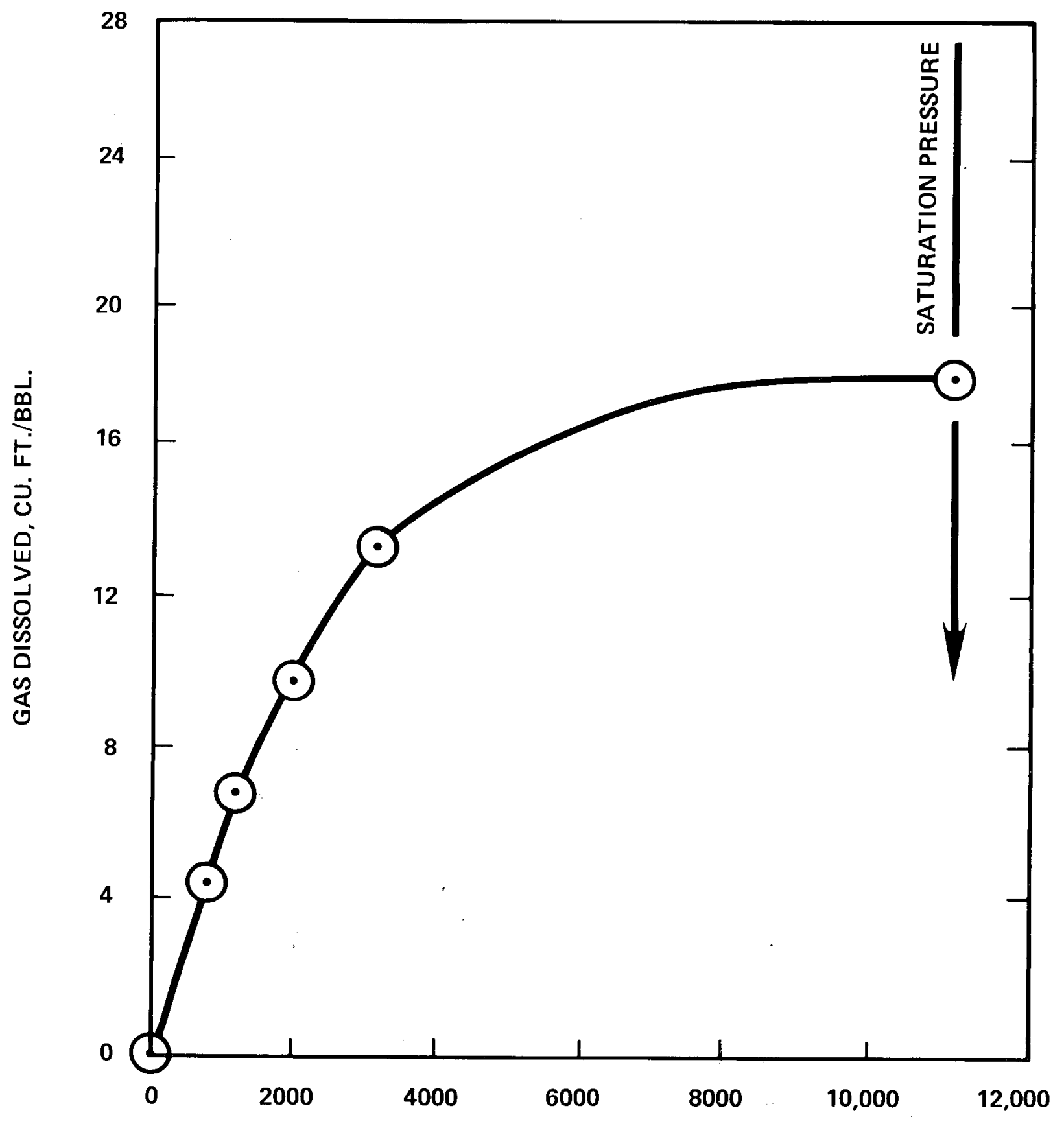

PRESSURE, PSIA 
FIGURE 17

\section{FLOW TO A WELL}

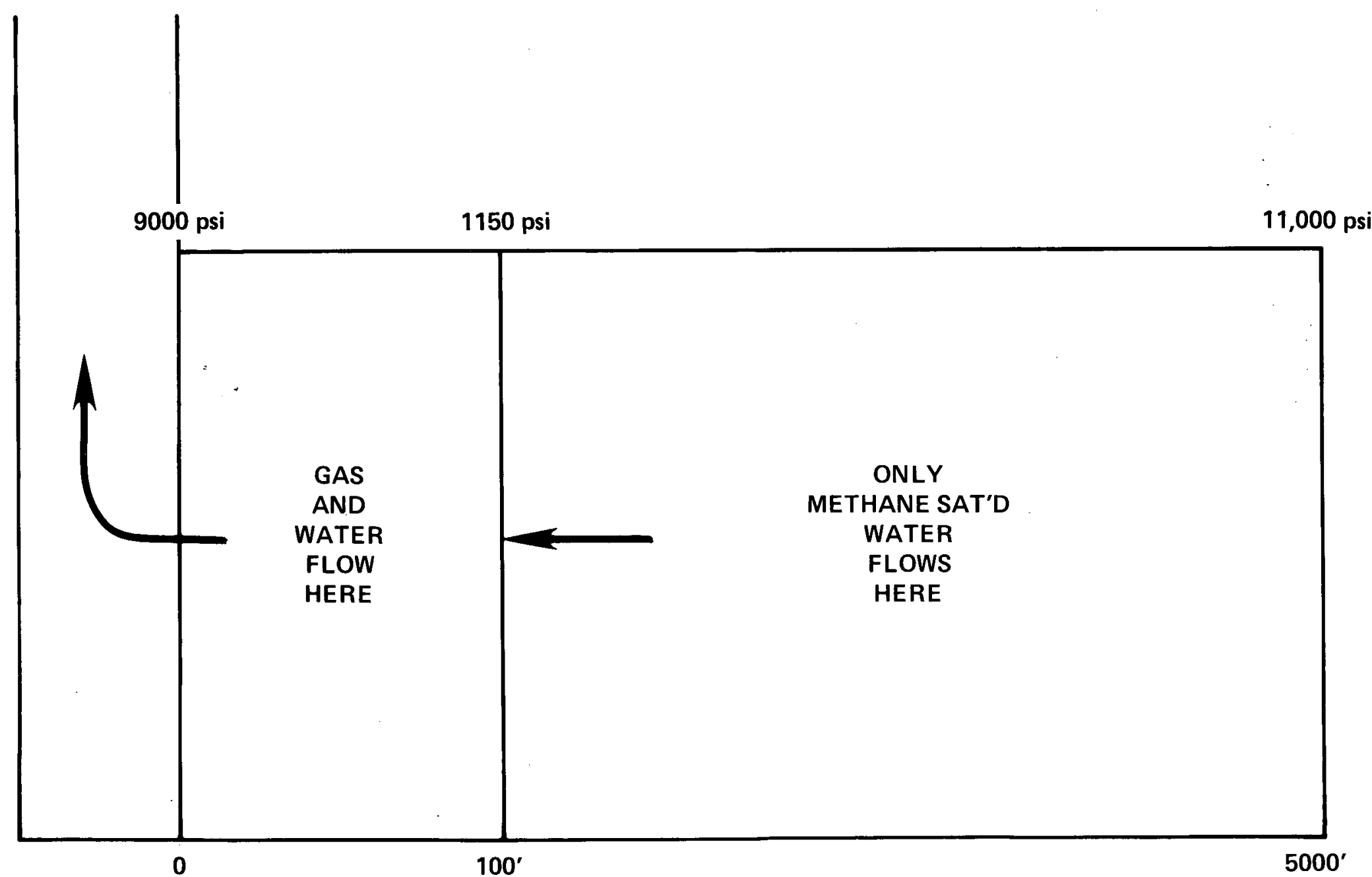


FIGURE 18

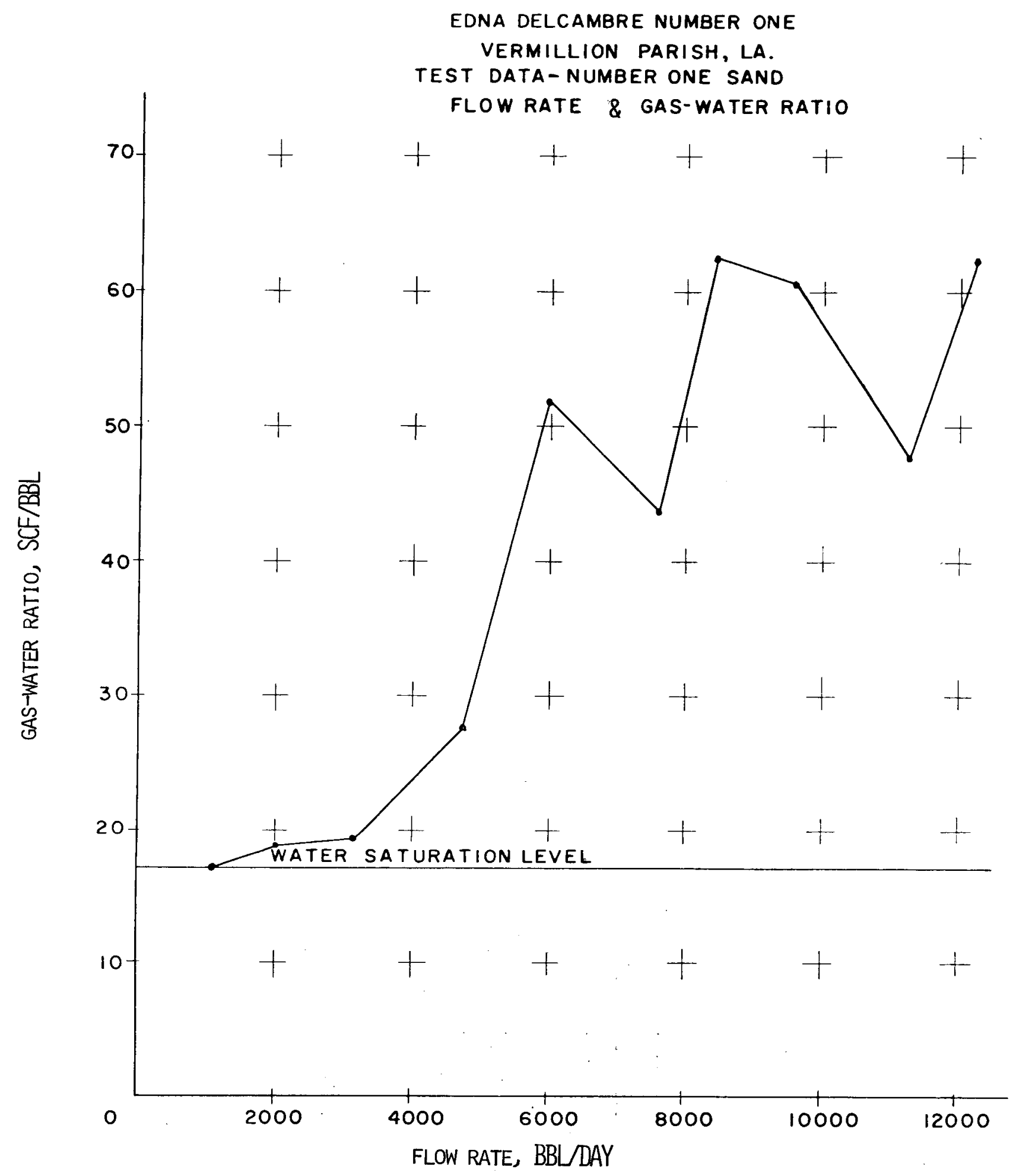




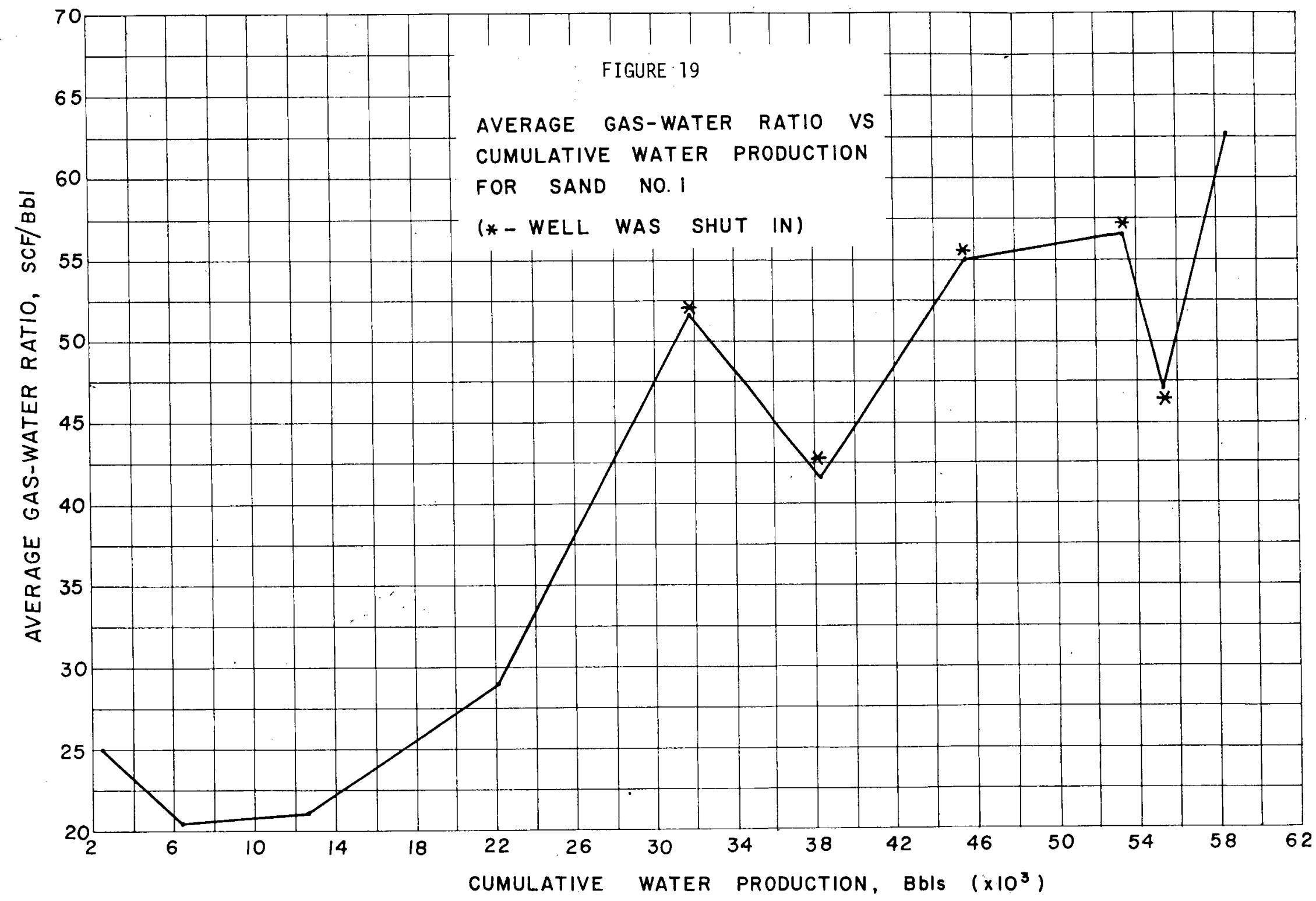


FIGURE 20

EDNA DELCAMBRE NUMBER ONE

VERMILLION PARISH, LA.

TEST DATA - NUMBER THREE SAND

FLOW RATE \& GAS-WATER RATIO

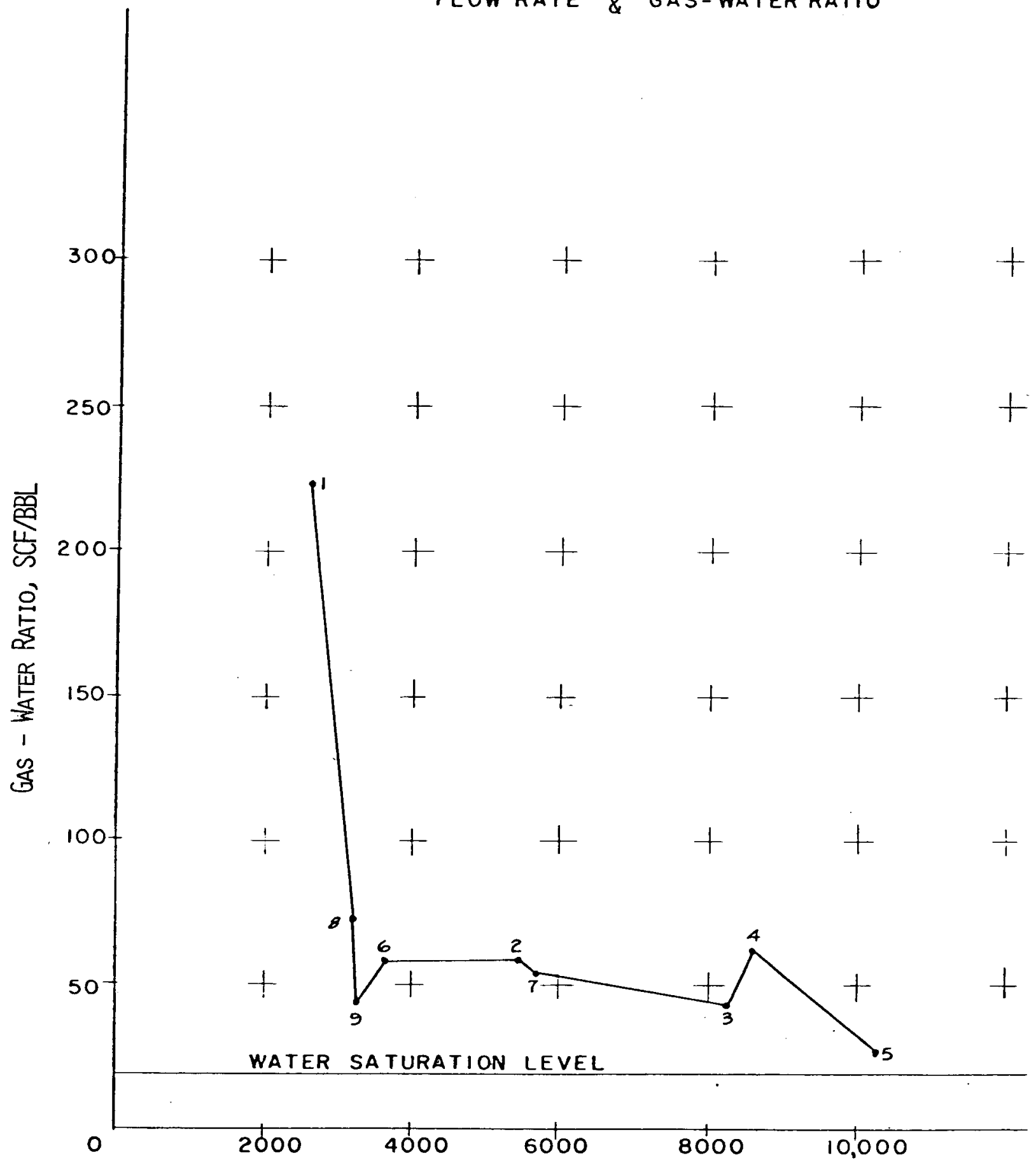

FLOW RATE, BBL/DAY 
FIGURE 21

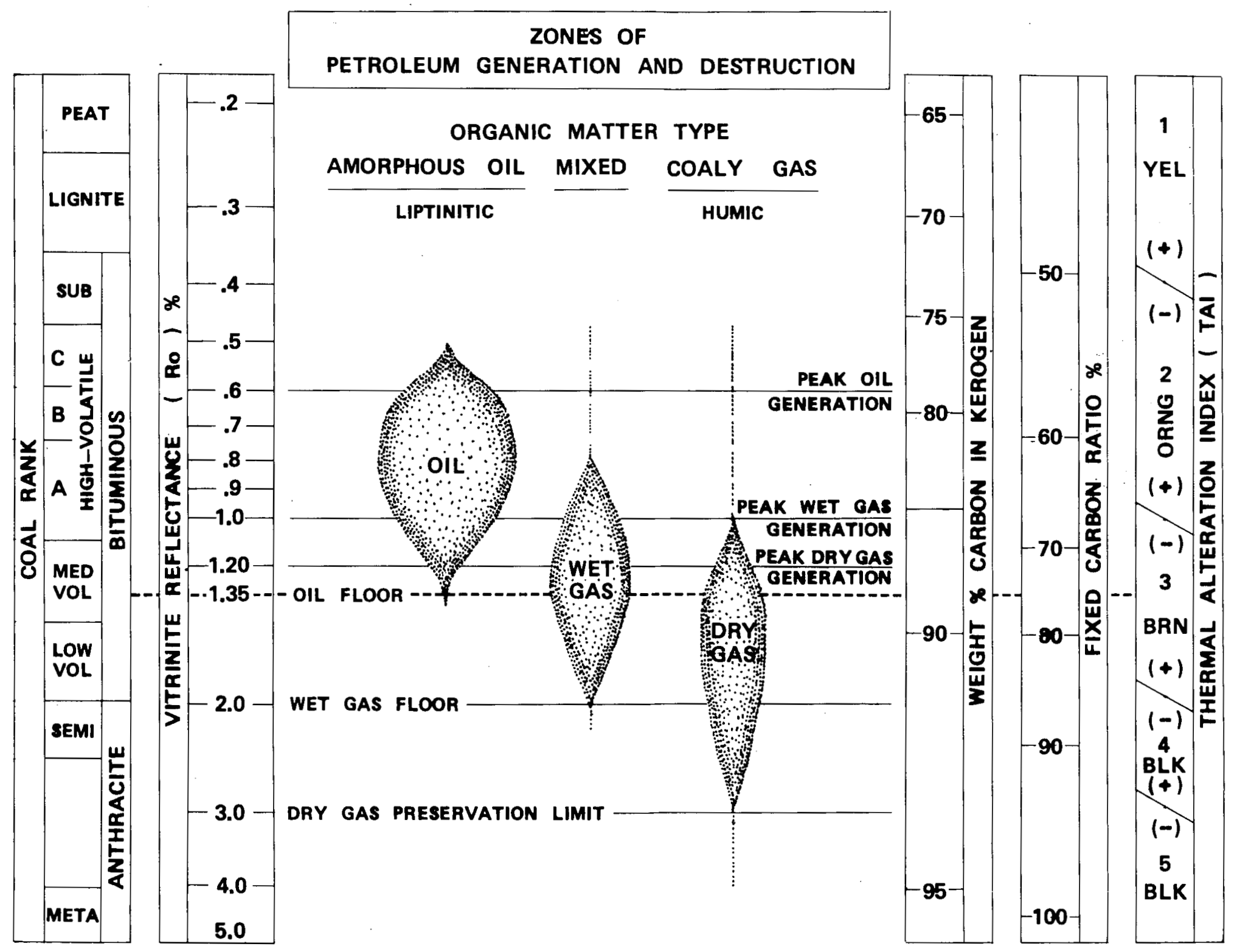


FIGURE 22

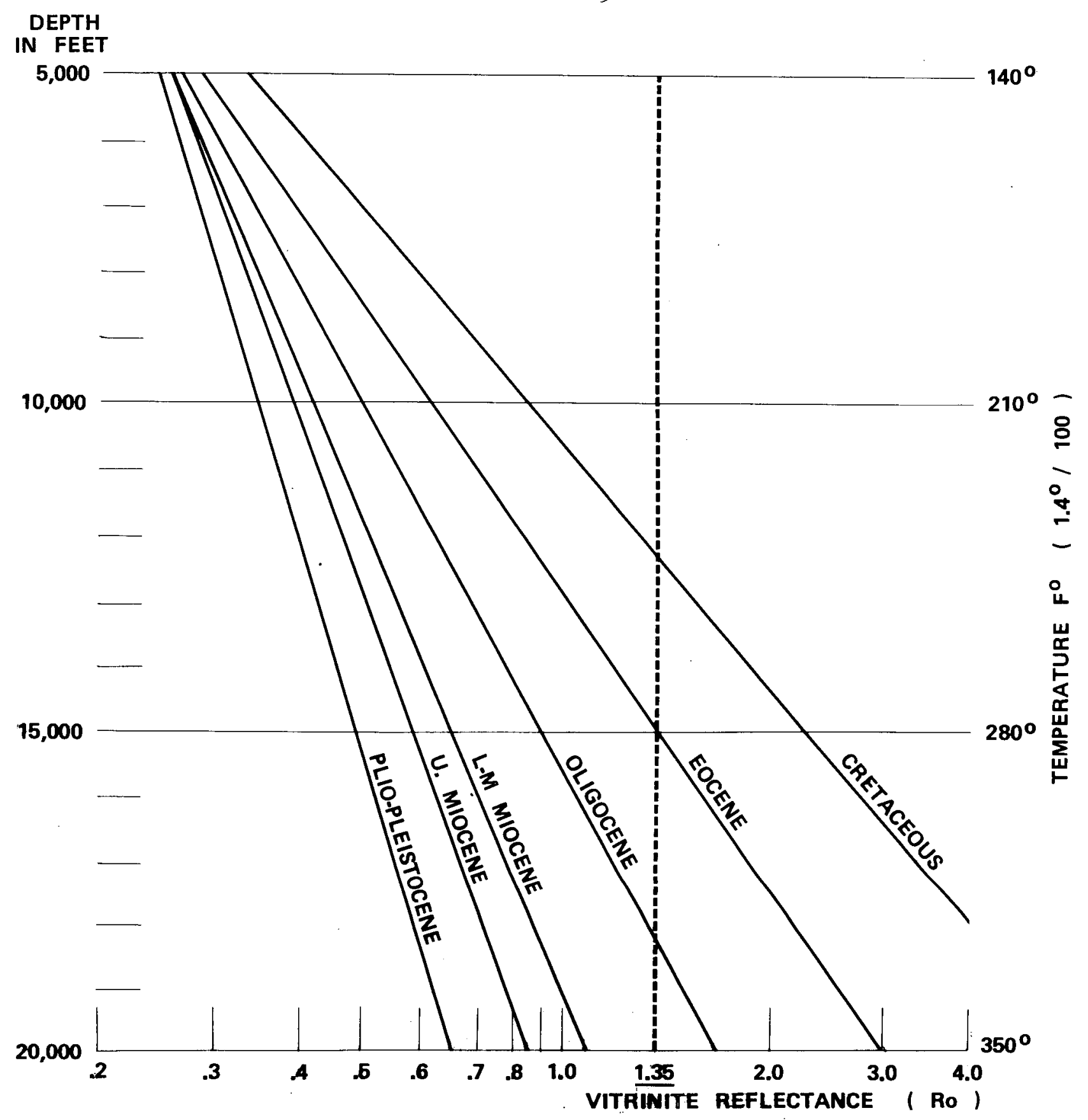


United States

Department of Energy

Washington, DC 20545

\section{FIRST CLASS MAIL}

Official Business

Penalty for Private Uso, $\$ \mathbf{3 0 0}$ 